\title{
Oligodendroglial Alterations and the Role of Microglia in White Matter Injury: Relevance to Schizophrenia
}

\author{
Li-Jin Chew $^{\text {a }}$ Paolo Fusar-Poli ${ }^{b}$ Thomas Schmitz ${ }^{c}$ \\ ${ }^{a}$ Center for Neuroscience Research, Children's Research Institute, Children's National Medical Center, \\ Washington D.C., USA; ${ }^{b}$ Department of Psychosis Studies, Institute of Psychiatry, King's College, London, UK; \\ 'Klinik für Neonatologie, Campus Virchow Klinikum, Charité - Universitätsmedizin Berlin, Berlin, Germany
}

\section{Key Words}

Cytokine · Development · Injury · Inflammation · Microglia ·

Myelination · Oligodendrocyte · Psychosis · Risk ·

Schizophrenia

\begin{abstract}
Schizophrenia is a chronic and debilitating mental illness characterized by a broad range of abnormal behaviors, including delusions and hallucinations, impaired cognitive function, as well as mood disturbances and social withdrawal. Due to the heterogeneous nature of the disease, the causes of schizophrenia are very complex; its etiology is believed to involve multiple brain regions and the connections between them, and includes alterations in both gray and white matter regions. The onset of symptoms varies with age and severity, and there is some debate over a degenerative or developmental etiology. Longitudinal magnetic resonance imaging studies have detected progressive gray matter loss in the first years of disease, suggesting neurodegeneration; but there is also increasing recognition of a temporal association between clinical complications at birth and disease onset that supports a neurodevelopmental origin. Presently, neuronal abnormalities in schizophrenia are better understood than alterations in myelin-producing cells of the
\end{abstract}

brain, the oligodendrocytes, which are the predominant constituents of white matter structures. Proper white matter development and its structural integrity critically impacts brain connectivity, which affects sensorimotor coordination and cognitive ability. Evidence of defective white matter growth and compromised white matter integrity has been found in individuals at high risk of psychosis, and decreased numbers of mature oligodendrocytes are detected in schizophrenia patients. Inflammatory markers, including proinflammatory cytokines and chemokines, are also associated with psychosis. A relationship between risk of psychosis, white matter defects and prenatal inflammation is being established. Animal models of perinatal brain injury are successful in producing white matter damage in the brain, typified by hypomyelination and/or dysmyelination, impaired motor coordination and prepulse inhibition of the acoustic startle reflex, recapitulating structural and functional characteristics observed in schizophrenia. In addition, elevated expression of inflammation-related genes in brain tissue and increased production of cytokines by blood cells from patients with schizophrenia indicate immunological dysfunction and abnormal inflammatory responses, which are also important underlying features in experimental models. Microglia, resident immune defenders of the central nervous system, play important roles in the development and protec-

\section{KARGER}

E-Mail karger@karger.com

www.karger.com/dne
(C) 2013 S. Karger AG, Basel

0378-5866/13/0353-0102\$38.00/0
Li-Jin Chew, $\mathrm{PhD}$

Center for Neuroscience Research, Children's Research Institute

Children's National Medical Center

Washington DC, 20010 (USA)

E-Mail LChew@childrensnational.org 
tion of neural cells, but can contribute to injury under pathological conditions. This article discusses oligodendroglial changes in schizophrenia and focuses on microglial activity in the context of the disease, in neonatal brain injury and in various experimental models of white matter damage. These include disorders associated with premature birth, and animal models of perinatal bacterial and viral infection, oxygen deprivation (hypoxia) and excess (hyperoxia), and elevated systemic proinflammatory cytokine levels. We briefly review the effects of treatment with antipsychotic and anti-inflammatory agents in models of perinatal brain injury, and comment on the therapeutic potential of these strategies. By understanding the neurobiological basis of oligodendroglial abnormalities in schizophrenia, it is hoped that patients will benefit from the availability of targeted and more efficacious treatment options.

Copyright $\odot 2013$ S. Karger AG, Basel

\section{Introduction}

Schizophrenia is a severe mental illness that represents one of the most heterogeneous mental disorders in human disease. The heterogeneity of symptomatology and etiology is likely to reflect multifactorial causes, and at the neurobiological level, the involvement of a variety of nonneuronal cell types in multiple anatomical regions of the brain. Patients diagnosed with schizophrenia frequently present with positive and negative symptoms of abnormal brain function, i.e. hallucinations and thought disorganization, as well as social withdrawal and apathy, even extending to mood disorders such as depression and anxiety (table 1). Cognitive ability, including facets of attention focus and working memory, which subserve higher levels of executive function, is consistently impaired in schizophrenia. Although gray matter changes are an important component in the pathology of schizophrenia, emerging evidence of defects in white matter (WM) integrity, including the fiber bundles of the internal capsule and corpus callosum, have shown that changes in WM structure are strongly associated with abnormal or decreased structural and functional connectivity $[1,2]$. Structural connectivity refers to macroscopic physical wiring while functional connectivity is defined by the neural dynamics of temporally and functionally related but spatially remote physiological events [3]. In addition, there is also evidence for altered axonal conduction velocity in schizophrenia patients [4]. Abnormalities in connectivity are found to underlie cognitive impairment at disease onset [5]. The relationship between WM integrity and executive function is now well established in both infants and the aged $[6,7]$. Thus the origin of these WM abnormalities in the pathology of schizophrenia is a primary area of concern. At present, more evidence supports the neurodevelopmental rather than the neurodegenerative theory, as experimental models of maternal infection and perinatal hypoxia-ischemia have been shown to lead to abnormal WM development. Indeed, obstetric complications and prenatal infection are predisposing factors to neurological deficits, while inflammation and immune activation in the central nervous system (CNS) are also among the shared characteristics in patients and in experimental models. The present article will attempt to highlight the role of CNS inflammatory mediators in the generation of perinatal WM lesions, which ultimately lead to behavioral characteristics that resemble functional aspects of schizophrenia. Specifically, we will attempt to address the oligodendroglial and microglial abnormalities associated with the onset of the disorder in these models as well as review some recent findings in pharmacological approaches to intervention.

\section{The Prodromal High-Risk Phenotype and Onset of Schizophrenia}

Based on clinical studies over the last 2 decades, accumulating evidence has indicated that schizophrenia develops by a process that may be divided into at least 3 stages: the prodrome (prepsychotic), the first episode (psychosis onset), and chronic illness [8]. The prodromal phase typically starts in early adolescence or late childhood, during which signs of delayed neurodevelopment, presentation of attenuated psychotic symptoms, or a significant decrease in functioning (table 1) may be identified as risk indicators for future psychosis. A widely used approach to the investigation of this phase, variably termed ultrahigh risk (UHR), clinical high risk or at risk mental state, enables researchers to assess psychopathological and neurobiological characteristics of the putative prodromal state in longitudinal studies. Thus, individuals at high risk, i.e. who are presenting with subthreshold and attenuated psychotic symptoms, have an enhanced likelihood of developing a psychotic disorder over time. The rate of transition to psychosis, however, measures predictive value within a defined, and often relatively short, period of time. This rate depends not only on inclusion criteria but also on patient sampling and treatments used. A recent meta-analysis of more than 2,500 high-risk subjects quantified such vulnerability with a transition risk 
Table 1. Summary of symptoms and core abnormalities in schizophrenia

\begin{tabular}{|c|c|}
\hline Property & Abnormalities in schizophrenia \\
\hline Risk factors & $\begin{array}{l}\text { Obstetric complications (e.g. bleeding during pregnancy, abnormal fetal growth, premature labor } \\
\text { and neonatal asphyxia) }[56,57] \\
\text { Maternal infection, premature labor and delivery [55] } \\
\text { Familial disease [306] }\end{array}$ \\
\hline $\begin{array}{l}\text { Prodromal/ } \\
\text { high-risk state/ } \\
\text { psychosis risk syndrome }\end{array}$ & $\begin{array}{l}\text { Poor prenatal care (e.g. low socioeconomic status, inadequate prenatal nutrition, maternal obesity } \\
\text { and substance abuse) [307, 308] } \\
\text { (1) Attenuated psychotic symptoms, e.g. unusual thoughts, perceptual abnormalities, suspiciousness } \\
\text { (2) Brief and self-limiting psychotic symptoms, e.g. delusions } \\
\text { (3) Disturbances in cognitive processing, impaired speech fluency and self-perception } \\
\text { (4) Negative symptoms, e.g. awkwardness, anxiety, decreased expression of emotion, decreased } \\
\text { engagement and role functioning [9,309] } \\
\text { (5) Reduction in WM volume prior to onset of psychosis [42] }\end{array}$ \\
\hline Brain structure & $\begin{array}{l}\text { Low cerebral volume, higher lateral ventricle volume, reduced WM volume }[20,312] \\
\text { Altered WM connectivity and ultrastructure [2] } \\
\text { Reduced FA and increased radial diffusivity in WM regions, including corpus callosum, measured by } \\
\text { DTI indicating compromised WM integrity even in early stages of schizophrenia [312] }\end{array}$ \\
\hline $\begin{array}{l}\text { Cellular and } \\
\text { biochemical changes }\end{array}$ & $\begin{array}{l}\text { Lack of normal developmental increase in mature oligodendrocytes in high-risk individuals, resulting in } \\
\text { loss of myelin-producing cells }[23,67,312] \\
\text { Stem cells from schizophrenia patients generate a larger pool of proliferating progenitor cells with } \\
\text { reduced cell cycle period [53] } \\
\text { Impaired monocyte activation, reducing pathogen clearance that can cause low-grade inflammation } \\
\text { [111] } \\
\text { Neuroinflammation and increased microglia activation, dysregulation of chemokine and cytokine } \\
\text { production }[109,110,313]\end{array}$ \\
\hline
\end{tabular}

increasing from $18 \%$ after 6 months up to $36 \%$ after 3 years since the first presentation [9]. Notably, most of the subjects (73\%) who will later develop a psychotic illness will transit to an ICD/DSM schizophrenic psychosis rather than to an affective psychotic illness $(11 \%$, risk ratio $=$ 5.4) [10]. The latter is a condition showing both schizophrenic (psychotic) and mood disorder (affective) components, and is itself characterized by two subtypes: a depressive subtype and a bipolar subtype with manic episodes. Because of the controversy about the inclusion of schizoaffective disorders as a variant of schizophrenia, ongoing efforts primarily focus on the clarification of the diagnoses of these complex and often overlapping conditions - schizophrenia, schizoaffective and mood disorders - since very few studies investigate their neurobiology as separate conditions [11].

The high-risk state (for a comprehensive review, see Fusar-Poli et al. [12]) is usually associated with distress symptoms, impaired quality of life, and subtle, albeit significant, deficits in cognitive functioning (table 1). At the neurobiological level, there are gray matter reductions in the temporoparietal, prefrontal and limbic cortex [13], as well as altered function and neurochemistry [14]. Some of these brain abnormalities are associated with the high- 
risk state, while others can predict the longitudinal development of psychosis [15]. Given the low success rate of postonset intervention, the shift toward preonset strategies has become a subject of intense debate. Understandably, classification schemes for the disorder have greatly increased in complexity [16], and interest in criteria for the prepsychotic phases has grown to an extent that a new diagnostic category is being proposed for inclusion in the forthcoming DSM-5 [17]. New treatments are under investigation to reduce the disability associated with highrisk symptoms or to prevent the frank onset of illness [18]. Given the significant burden of social and clinical efforts paid to the treatment of chronic schizophrenia, the identification of core neurobiological alterations predating the onset of the illness is of great economic relevance. Presently, studies addressing neuronal development during this phase are very promising [19]. In contrast, the investigation of WM alterations during the early psychotic phases is still in its infancy, but is rapidly gaining momentum. We will try to address core neurobiological issues regarding WM damage in the following sections.

\section{Relationship between WM Alterations and Schizophrenia: Neurobiological Basis for a Developmental Origin}

It is well established that gray and WM volume is decreased in the brains of schizophrenia patients [20] and that tissue loss in brains of patients with schizophrenia includes temporal lobe reduction [21], enlarged lateral or third ventricles [22], and reduced frontal lobes [23]. Following the onset of disease, the progressive changes in brain tissue volume, detected by magnetic resonance imaging (MRI) in longitudinal studies, suggest a degenerative process, although histopathologic hallmarks of destruction and degeneration, such as neuronal death and gliosis, are noticeably lacking in schizophrenia [24]. Given that gray matter changes are known to precede clinical symptoms and psychotic illness [25], and that individuals who later developed frank illness showed cognitive and motor abnormalities previously at a young age, it is now widely believed that such changes are derived from a neurodevelopmental origin. This hypothesis proposes that some cases of schizophrenia result from early brain insult, either pre- or perinatal, which negatively impacts brain development, resulting in abnormalities in the mature brain [26]. Indeed, preterm infants with WM injury and chronic lung disease display brain tissue volume alterations [27], and WM injury in the premature infant has

Myelin Development and Microglia in Schizophrenia been found to subsequently lead to reduced gray matter volume at term [28]. These provide a strong argument for a need to better understand the developmental aspect of WM changes in approaching the etiology of schizophrenia.

Myelin functions as electrical insulation for axons, which maintains the amplitude and conduction velocity of the propagating action potential during saltatory conduction. WM of the CNS consists of axon bundles ensheathed by the compacted processes of a distinct class of myelin-forming neuroglia known as oligodendrocytes. Specific abnormalities in myelin are increasingly observed in patients with schizophrenia [29], including decreased numbers of oligodendrocyte cells [30], increased apoptotic oligodendrocytes, axonal atrophy and swelling of oligodendrocyte processes [31]. Changes are also found in the expression of oligodendrocyte-associated genes [32], with decreases in specific myelin proteins located within myelin sheaths (myelin and lymphocyte protein and myelin-associated glycoprotein; table 1) [33]. Analysis of brain microstructure by MRI techniques such as diffusion tensor imaging (DTI) has revealed reduced fractional anisotropy (FA) in bipolar and paranoid schizophrenia patients [34]. FA measures the directionality of water movement within spaces between axons, and thus provides structural information regarding WM tract integrity, density or organization. MRI has revealed deficiencies in patients in interhemispheric connectivity [35], particularly within the myelin-rich areas of the corpus callosum [36] and cingulum [37]. As expected, some changes have been associated with motor dysfunction [38] and more frequently, with deterioration of higher executive functions [39]. WM abnormalities are already detectable in UHR subjects with prodromal symptoms, showing lower WM volume in the temporal lobe [40], which appear to progress. Based on DTI analysis of this region, the reduction in FA in the UHR group compared with healthy controls was smaller than for first-episode schizophrenics [41], and longitudinal DTI studies in the UHR group confirmed the progressive reduction in FA in those who eventually developed psychosis [41]. In fact, growth of the WM was found to be significantly attenuated over time in UHR adolescents [42], which suggests that developmental abnormalities may indeed contribute to changes in brain structure at the time of disease onset [43].

The cellular alterations that underlie reduced myelination and delayed WM development is therefore a subject of great importance. In the myelin-containing WM of the CNS, the normal developing oligodendrocyte undergoes 
dramatic morphological changes as it develops from a spindle-shaped, proliferative oligodendrocyte progenitor cell (OPC) with few cellular extensions to a branched preoligodendrocyte and membranous postmitotic myelinating oligodendrocyte (fig. 1). These changes are accompanied by the stage-specific expression of cell surface and myelin component proteins, which are widely used to identify the discrete phases of cellular maturation. As many of these markers (fig. 1) were originally and extensively characterized with rat tissue culture and rodent brain histology, their applicability to studies of the human WM tissue warrants careful analysis [44]. Olig2 (fig. 1), a transcription factor essential for specification and maturation of the oligodendrocyte lineage [45-47], is widely used in the characterization of lineage changes in development and disease. A single nucleotide polymorphism in the Olig2 gene, identified as a risk variant, was recently found by a DTI study to be associated with reduced WM integrity [48]. Although its role is still not understood, this is consistent with the relationship between alterations of this cell lineage and risk of schizophrenia. In the developing human brain, the WM is vulnerable to hypoxia-ischemia and oligodendrocyte loss by oxidative damage at 28-32 weeks of postconceptional age, when late oligodendrocyte progenitors, or O4-expressing preoligodendrocytes, are abundant [49, 50]. Studies have shown that early postnatal ages of the rat and human infant overlap in specific developmental windows

Fig. 1. Schematic representation of the changes in morphology and gene expression during oligodendroglial development (a) and microglial activation (b), with characteristic stage- or state-specific proteins presented in boxes. Exposure of susceptible cells (a) to activated cells (b) contributes to changes in WM integrity. a Damage to immature stages of the oligodendroglial lineage leads to compromised WM integrity. The OPC develops from a neural precursor as a proliferative, migratory cell which expresses surface antigens (e.g. NG2, PDGFR- $\alpha$ ) that are used as identifying markers to distinguish them from the postmitotic, morphologically complex and increasingly membranous immature oligodendrocyte and mature oligodendrocyte. Arrows between developmental stages in oligodendroglia denote the direction of lineage progression during maturation. OPCs and preoligodendrocytes possess the capacity for self-renewal (circular arrows), whereas this ability is lost in immature and mature oligodendrocytes. The oligodendroglial lineage is characterized by monoclonal antibodies against surface gangliosides (GD3, A2B5, RIP), sulfatides (O4), and the galactolipid galactocerebroside (GalC). Progenitors are further identified by the NG2 proteoglycan and platelet-derived growth factor receptor-alpha (PDGFRa). Myelin-specific proteins are abbreviated as follows: $\mathrm{CNP}=2^{\prime}, 3^{\prime}$-cyclic nucleotide $3^{\prime}$ - phosphodiesterase; $\mathrm{MAG}=$ myelin-associated glycoprotein; $\mathrm{MOG}=$ myelin of equivalence with regard to the state of maturation of the oligodendroglial lineage. Additionally, oligodendrocyte development in the gray matter regions, which occurs later than in WM, further extended the anatomical regions and periods of susceptibility to oligodendroglial damage due to hypoxia-ischemia [44]. In addition to loss of mature oligodendrocytes, there is increasing evidence of abnormalities in the development of the oligodendroglial lineage. In an effort to understand changes in signaling mechanisms in schizophrenia, a microarray gene expression study using samples from a tissue bank revealed increased expression of cell cycle proteins, namely cyclins D1 and D2, in the anterior cingulate gyrus of schizophrenia patients compared with controls [51], accompanied by decreased levels of cyclin-dependent kinase inhibitors p27Kip1 and p57Kip2. Statistical analysis drew positive correlations between p27Kip1, p57Kip2 and oligodendroglial marker expression, indirectly suggesting the possibility of re-entry of postmitotic oligodendrocytes into the G1 phase of the cell cycle [51]. Analysis of gene expression at the RNA level in the internal capsule of schizophrenia patients revealed increased levels of genes involved in the maintenance of cell cycle activity, along with decreased caspase 3 and genes responsible for cell cycle arrest [52]. These observations suggest that oligodendrocytes in healthy controls turned over more rapidly than those in schizophrenia, and that cell cycle exit and maturation of oligodendrocyte precursors are impaired [52].

oligodendrocyte glycoprotein. The nuclear transcription factor OLIG2 is widely used for the histological identification of oligodendroglial cells, because of its lineage-restricted expression throughout oligodendrocyte progenitor development. The O4+ stage oligodendroglial cell has been found to be particularly susceptible to perinatal damage, as shown with the solid bracket [201]. The possibility of hyperoxia-induced damage to NG2+ cells [176] has been included by the dashed partial bracket. b Resting or ramified microglia receive environmental signals that transform the surveying microglia to an activated phenotype. Microglia under activation and deactivation, and distinct polarizing stimuli may induce either classically activated, proinflammatory M1 state or alternatively activated anti-inflammatory M2 state. M1 macrophage/microglia produces proinflammatory cytokines and oxidative metabolites, and may damage healthy neural cells while protecting against tumors and pathogens. M2 microglia are anti-inflammatory, and promote tissue repair, remodeling and angiogenesis. The dashed line between M1 and M2 denotes less easily defined intermediate phenotypes. Boxes list CD antigen proteins, enzymes and cytokines whose expression and/or secretion characterize distinct microglial activation states. MMP $=$ Matrix metalloproteinase; TGF- $\beta=$ transforming growth factor $\beta ; \mathrm{Fc} \gamma \mathrm{R}=$ $\mathrm{Fc} \gamma$ receptor $[78,83]$. 


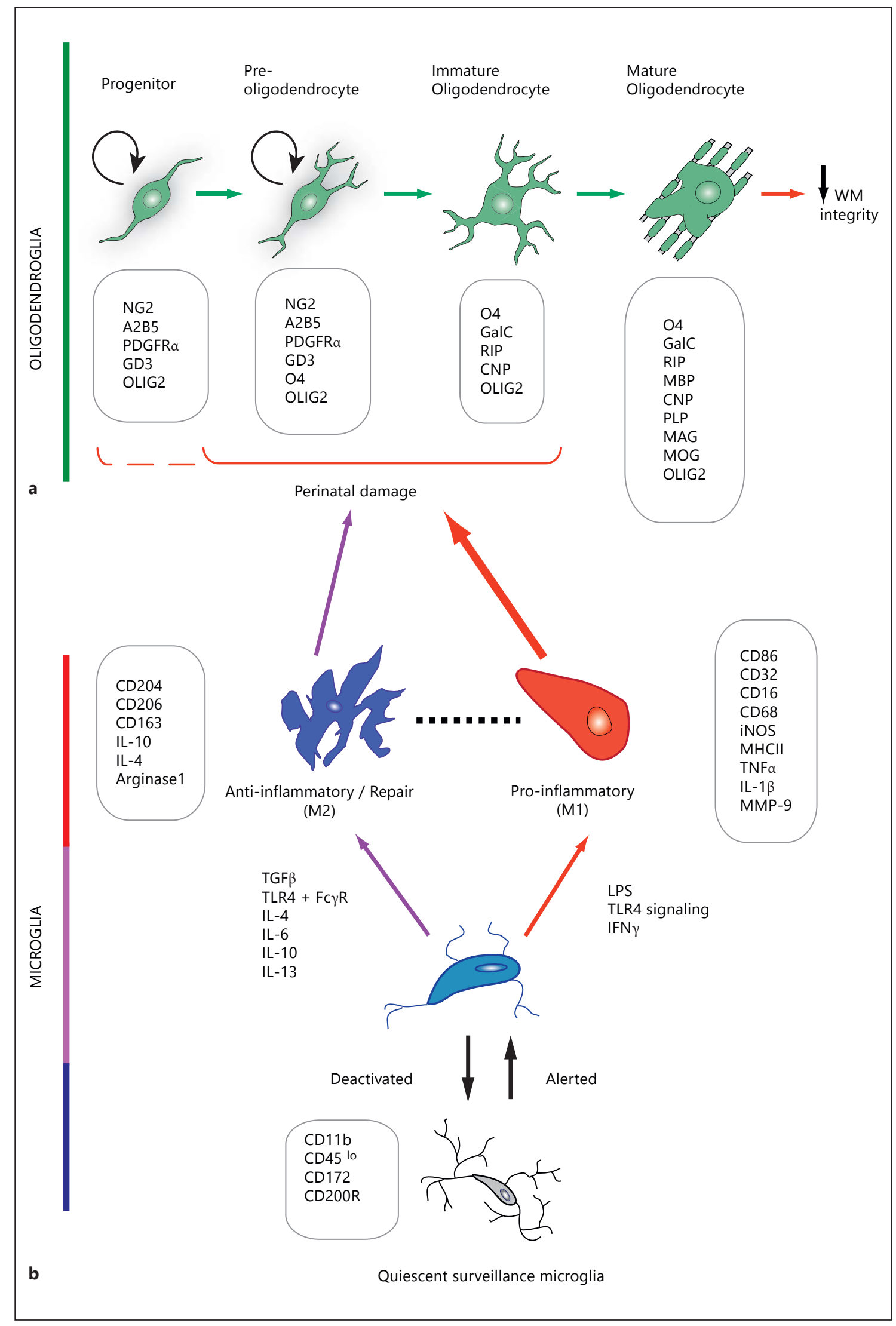


Consistent with this finding of abnormal cell cycle properties, a recent study has found that neural biopsies from schizophrenia patients show increased proliferation when cultured, and neural stem/progenitor cells that are derived from these biopsies showed increased proliferation rate and altered cell cycle dynamics [53], indicating changes in developmental characteristics. These results support the notion that cellular changes leading to WM abnormalities in schizophrenia could include not only cell death in the lineage but also delayed maturation of the progenitor cell population.

\section{Developmental Origins: Periventricular WM Damage and Schizophrenia}

The neurodevelopmental hypothesis of schizophrenia posits that early disruption of brain development can modify the trajectory of subsequent brain growth. Numerous studies have analyzed risk factors for schizophrenia that impact brain development during early life. Epidemiological data have revealed prenatal nutritional deficiency [54], prenatal famine, prenatal infection [55], pregnancy and birth complications as important risk factors for schizophrenia, strongly implicating a developmental basis for the illness. It is well established that obstetric complications occurred in many schizophrenic patients $[56,57]$. These include: (a) problems in pregnancy, e.g. bleeding, antepartum hemorrhage, gestational diabetes, and rhesus incompatibility; (b) abnormal fetal growth, e.g. congenital malformations and abnormal head circumference, and low birth weight, and (c) problems with delivery, e.g. premature rupture of membranes, preterm birth, neonatal asphyxia (hypoxia-ischemia), and emergency cesarean sections [58-60]. Periventricular WM injury (PWMI) or damage, a frequent cause of brain injury in premature or preterm infants, consists of a spectrum of cerebral injury which ranges from necrotic foci to diffuse myelination defects, generally presenting as lesions adjacent to the lateral ventricles [61]. As will be discussed later in relation to periventricular leukomalacia (PVL), the consequences of PWMI range from mild to severe motor deficits (such as in cerebral palsy), including cognitive and learning disabilities [62, 63], but the contribution of PWMI to behavioral abnormalities, without cerebral palsy, is unclear.

Many different animal models have been developed for the study of schizophrenia, which target both gray matter and WM components: these include the pharmacological manipulation of dopaminergic, glutamatergic, serotoninergic and GABAergic neurotransmitter systems, as well as genetic disruption of specific genes. Of the genes consistently associated with schizophrenia, i.e. Neuregulin, Akt,
Disrupted in Schizophrenia (DISC) and dysbindin, both Akt and DISC1 have been implicated in WM function. $\mathrm{Akt} / \mathrm{mTOR}$ signaling is critical for oligodendrocyte development [64], while a common missense variant in DISC1 has been linked with WM integrity and schizophrenia [65]. In addition, experimental animal models have been developed that emulate many of the perinatal exposures arising from obstetric complications mentioned above, and these have proven to be highly informative toward the study of premature brain lesions. Despite substantial support for the neurodevelopmental basis of schizophrenia, the advent of high-resolution, noninvasive imaging techniques like MRI has facilitated the re-emergence of longitudinal evidence for neurodegeneration, with enlarged brain ventricles [66] and reduced tissue volume [23, 67] during the first years of disease onset. These findings of progressive gray matter loss in some patients have prompted the combined view of schizophrenia as a disease with both neurodevelopmental and neurodegenerative features. Toward the neurodevelopmental theory of schizophrenia, however, both prenatal and neonatal lesion models are of immense value, as the delayed onset of symptoms corresponds to the manifestation of schizophrenia in humans. Many of these perinatal lesions in the CNS of rodents, designed to mimic PWMI in various forms, invoke an inflammatory response and WM injury in a way that is also detected as dysmyelination in the adult CNS. These paradigms of maternal or neonate infection, hypoxiaischemia, hyperoxia and cytokine injection, will be discussed further in subsequent sections.

\section{Inflammation, Microglia and WM Disease}

Cytokines are critical mediators of early defense mechanisms against infectious agents. These low-molecularweight proteins are secreted in response to environmental stimuli by many cell types, besides typical immune cells like microglia, macrophages and lymphocytes. In contrast to hormones, the action of cytokines is not endocrine, but instead autocrine or paracrine. Their roles in both immune defense and neural cell development are nonetheless wide ranging, including recruitment of lymphocytes, regulation of immune cell homeostasis, and cell survival. In the CNS, cytokine activity in the context of their target cells displays remarkable pleiotropy, as their receptors are also expressed by glial and neuronal cell types [68]. Cytokine and cytokine receptors are expressed during fetal brain development in both rodents and humans, suggesting roles in normal neural cell development 
$[69,70]$. However, abnormal placenta levels of proinflammatory cytokines such as TNF- $\alpha$ and IL-6, elevated as a result of prenatal inflammation induced by lipopolysaccharide (LPS) or malnutrition, lead to increased vulnerability to complex brain disorders such as schizophrenia [71]. Cytokines (e.g. TNF- $\alpha$, IFN- $\gamma$, IL-1 $\beta$, IL-6, IL-10) mediate early defenses during infection and injury; they regulate the differentiation and activation of cells of the immune system, recruiting and activating lymphocytes through the delicate balance between pro- and anti-inflammatory signals. In pathological conditions, cytokines can affect nonimmune cell types directly by modulating gene expression and development [72], regulating protein synthesis [73], inducing cell death $[74,75]$ and stimulating stress cascades [76], thereby resulting in disruption of neurodevelopmental processes.

Inflammation in the CNS occurs in disease and injury, and involves the activity of microglia, which are resident immune cells of the CNS. Microglia represent almost 10$20 \%$ of adult CNS cells and may be considered the CNS equivalent of macrophages. Unlike neural cells, microglia are of mesodermal origin, and they enter the CNS during fetal development. Activated microglia possess the abilities of cytokine production, antigen presentation and phagocytosis. Resting or ramified microglia send out multiple branched processes which sense changes in their microenvironment [77] (fig. 1). When potential threats are recognized, these processes retract and microglia become oriented toward the injury site [78]. Little is known about these ramified microglia, but new roles in neuroprotection are emerging. Microglial cells participate in developmental pruning of synapses [79] and even minimizing excitotoxicity in neurodegeneration [80]. When activated, ramified microglia take on an ameboid shape with short processes, and the changes associated with their activation, such as increased cytokine production and expression of 'hematopoietic' markers like CD45, MHC class II antigens, CD40 and CD86, are known to constitute early events in many disease models (fig. 1). Microglia sustain and propagate inflammation during autoimmune inflammation, and they are primary reservoirs of proinflammatory cytokines such as IL-6, TNF- $\alpha$ and even IFN- $\gamma$ [81]. They also act as antigen-presenting cells in the CNS [82]. For exhaustive coverage of the intricate mechanisms, receptors and signals that regulate microglia physiology, the reader is directed to a recent comprehensive review by Kettenmann et al. [83].

In the mature CNS, the transformation of the resting/ ramified microglial cell by environmental stimuli involves shortening of cellular processes, and acquisition of an ameboid shape with polarized protrusions for migratory and phagocytic activities. Like macrophages, microglial activation is not considered a series of discrete on/off states, but rather a large complex continuum of phenotypes. Simplistically, the extremes of these phenotypes, termed M1 and M2, as applied to macrophage activation, refer to classical proinflammatory activation and alternate anti-inflammatory states, respectively (fig. 1) [84]. During the course of activation, the resting or surveillance microglia progress through alerted, proliferative and executive phases [83]. The balance of these activated states - detrimental or beneficial - is determined by environmental stimulus and intercellular influence. It would not be unreasonable to infer that the outcome of microglial activation would also be regulated by anatomical location [85], signal specificity, intensity and other as yet uncharacterized factors. In fact, regional differences in the adult mouse brain have been reported that are amplified after systemic challenge with bacterial endotoxin. The microglia in WM and caudal areas of the CNS showed greater upregulation in markers of activation than in gray matter rostral regions [86], which was correlated with declining cerebellar integrity and motor function with age. This indicates preferential compartmentalization of microglial activity in the CNS and may explain the differential vulnerability of these distinct brain regions in aging, infection and injury.

In the context of development, the morphological classification of microglial cells also includes resting/ramified, intermediate and ameboid forms. Ameboid microglia are found in the developing rodent brain [87] which are derived from circulating monocytes invading the brain during embryonic and early postnatal life. They also perform multiple functions - MHC class I antigen presentation (restrictive elements for cytotoxic and suppressor lymphocytes), MHC class II molecular expression, and participation in the function and maturation of $\mathrm{T}$ lymphocytes [88]. Studies of early microglial colonization indicated successive waves of microglial population of the fetal human brain: ameboid microglia first invade the diencephalon and telencephalon at 5 gestational weeks, then a second wave migrates into the brain via the vasculature at 12 gestational weeks [89]. Using tomato lectin and CD68 to label total and activated microglia, respectively, Billiards et al. [90] observed in developing human brains that ramified microglia were only detected at the earliest age of 20 postconceptional weeks, and intermediate ameboid microglia were abundant in the cerebral WM from 23 to 35 postconceptional weeks. This coincides with the peak period of vulnerability to PVL (see below), 
which occurs between 24 and 35 weeks. Later in gestation, microglia are reduced, and, as in the adult rodent, most microglia appear ramified [91]. In addition, the numbers of activated microglia are higher in the prenatal brain, especially in the cerebral WM [92], suggesting involvement in PWMI of premature infants [89]. Thus, a functional relationship between microglia and different developing neural cells is proposed, which includes (a) phagocytosing debris resulting from apoptotic death and synaptic pruning [93] and (b) association with WM tracts [94] en route to the cerebral cortex, both with implications for normal maturation and myelination [95]. These relationships thus place the microglial cell in an unenviable position of a double-edged sword for developmental control and vulnerability to injury.

\section{Microglial Plasticity}

Although the NG2 chondroitin sulfate antigen (fig. 1) is widely recognized as a cellular marker for OPCs particularly in WM regions, studies have described the expression of this antigen in microglial cells after injury [96]. In a study of cells isolated from adult and fetal human brain tissue, it was reported that the large majority of NG2-expressing cells in fact belonged to the microglial lineage based on their expression of CD68 and CD11c [97]. Such observations have contributed to an intense interest in the significance of 'ectopic' NG2 expression, and in the plasticity and multipotency of microglia, which may be context-dependent and highly relevant to disease states. In a model of facial nerve axotomy in adult rodents, it was found that the NG2-expressing cells, which had encapsulated the axotomized facial motoneurons, were microglia identified by OX42 and lectin immunopositivity [98]. NG2 was found to be induced in activated microglial cells in pups and adult rats injected with LPS, the bacterial endotoxin commonly used to mimic bacterial infection in animal models of inflammatory disease (discussed below) [99]. LPS is known to stimulate the production and release of proinflammatory cytokines from microglia. When microglia were transfected with siRNA to attenuate the expression of NG2, nitric oxide synthase (NOS) and cytokine expression was silenced. This indicates that NG2 mediates the production of cytokines and NOS in activated microglia [99]. Genetic ablation of NG2 in mice reduces the proliferation and abundance of not only OPCs, but also pericytes and microglia in the demyelinated adult spinal cord, altering the course of injury by decreasing both damage and repair [100]. In addition to their ability to express NG2, microglia have also been shown in culture to express antigenic markers that are characteristic of OPCs and preoligodendrocytes, e.g. A2B5, O4 [101]. In this study, microglia were also capable of morphological plasticity, extending processes and expressing markers of neurons, oligodendrocytes and astrocytes [101]. However, these microglia did not show the expected characteristics of neurospheres generated from stem cells, as they lacked neural stem cell markers Musashi-1 and epidermal growth factor receptor [101]. Chronic exposure for more than 10 days to lowdose IFN- $\gamma$ induced microglia in culture to express neuronal markers, including $\gamma$-aminobutyric acid and glutamic acid decarboxylase 67, proteins typically found in interneurons, whereas low doses of IL- 4 instead induced the expression of oligodendrocyte markers and dendritic cell marker CD11c [102]. In an adult injury model under trimethyltin intoxication, OX42 and ED-1+ (CD68) microglia were found to express $\mathrm{O} 4$ and even APC/CC1, a marker of more mature oligodendroglia, together with nestin [103], prompting the authors to propose that this injury stimulus transforms two classes of glia - NG2+ progenitors and microglia - into ameboid cells with properties of both oligodendrocytes and monocytes. Taken together, these studies suggest that microglia possess the potential to directly alter the neural cell response to brain damage. In view of recent gene expression studies implicating defective progenitor cell differentiation in schizophrenia [104], it is possible that microglial activation and plasticity could contribute to such defects. Since many WM injuries are accompanied by increased numbers of NG2+ cells, it is clear that much more work is needed to understand the full extent of the role(s) of apparent microglial multipotency in the damage and recovery of various developmental and adult brain lesions, and the possibility of involvement of progenitor-like microglial activation states in schizophrenia.

Thus, at many levels, microglia help shape the inflammatory response to injury and participate in modulating WM damage in the developing brain $[105,106]$. There is evidence of both cytotoxicity to and protection/repair of cells of the oligodendroglial lineage by microglia, as the lack of TNF- $\alpha$ delays remyelination in the adult [107]. This feature of microglial activation underscores the complexity of cellular responses to microglia-activating stimuli. Their effects on oligodendrocytes have been found to be dependent upon the developmental stage of the oligodendrocytes [108], but much is still to be learned about microglia-oligodendroglia interactions in development and disease. Evidence of neuroinflammation and alterations in microglia have been found in schizophrenia patients $[109,110]$, although the anatomical regions ana- 
lyzed in these studies would implicate microglial activities in gray matter neuronal loss rather than WM changes. Nonetheless, findings of impaired monocyte activation in schizophrenia [111], which could lead to low-grade inflammation, suggest that the inflammatory environment could indirectly impact glial development and repair (table 1). In the following sections, we will highlight selected conditions of perinatal WM disease known to involve underlying inflammatory processes, as well as experimental models of developmental WM injury, with an emphasis on microglial properties and their detrimental effects on oligodendroglia in the CNS.

\section{PVL and Neurological Problems in Infants of \\ Premature Birth}

Maternal infections and inflammation during pregnancy are known to be associated with preterm labor, and brain injury is a common problem arising from these births [112]. Due to these complications, as many as 40 $50 \%$ of survivors of premature births that are delivered at very low birth weight (i.e., $<1,500 \mathrm{~g}$ birth weight) show developmental disabilities: 5-10\% develop cerebral palsy, $15-25 \%$ show major cognitive deficits, and over $50 \%$ receive specialized help at school $[113,114]$. Low birth weight is recognized as an important risk factor for respiratory distress syndrome, severe infections, and hypoxicischemic or hemorrhagic injury, all of which negatively impact healthy brain development [115]. The corpus callosum connects the majority of the neocortical structures and constitutes the largest WM fiber bundle in the human brain. Imaging studies in children, adolescents and adults have documented smaller corpus callosum size and altered diffusion patterns to be associated with preterm births [116]. Low FA values within multiple WM regions, including the corpus callosum, in brains of adolescents born prematurely at very low birth weight [117] are associated with impairment of motor function [118]. Deficits persist into adulthood [119], with cognitive ability, measured in IQ tests, found to be significantly impaired even by 19 years of age [120]. These young adults continue to show decreased FA in major WM tracts, indicating the lasting structural and functional impact of an adverse perinatal event [121].

In an infection, maternal tissue is capable of producing cytokines [122], and their potential transfer from mother to fetus and amniotic fluid may constitute a possible mechanism of fetal injury. During normal pregnancy, both pro- and anti-inflammatory cytokine responses are maintained, but anti-inflammatory cytokine production increases while proinflammatory cytokines decline with

Myelin Development and Microglia in Schizophrenia gestational age [123]. Therefore, preterm fetuses show a more robust proinflammatory response than term infants. It was found that the response to microbial invasion, as measured by IL-6 levels, was higher in umbilical cord plasma from preterm than term neonates [124]. This would suggest that, from a protective standpoint, premature brains are more vulnerable to inflammatory dysregulation and damage than term brains. Jeopardizing brain development greatly increases the chances of long-term psychiatric disorders, such as attention deficit/hyperactivity disorder (ADHD), anxiety disorders [125, 126], and schizophrenia spectrum disorders [127].

WM damage, which includes PVL in severe cases, is associated with hypomyelination and is recognized as the main pathology associated with neurological morbidities of premature birth [128]. PVL consists of focal necrosis, diffuse reactive microgliosis and astrogliosis in the WM surrounding the ventricles $[49,90]$. Very preterm infants born at $<30$ gestational weeks or with very low birth weight $(<1500 \mathrm{~g})$ are at high risk of PVL. The causes of PVL are multifactorial, with primary contributions from ischemia/reperfusion at birth and inflammation arising from maternal and perinatal infection, hypocapnia and hyperoxia [128, 129]. The cytokines IL-1, -2 and -6 and TNF have been detected in the microglia of newborns with PVL $[130,131]$. Similarly, elevated apoptotic activity and high intracranial expression of inflammatory cytokines have been found to be associated with cystic WM damage in preterm infants suffering from posthemorrhagic hydrocephalus $[132,133]$. Because cystic lesions of PVL have since declined in occurrence due to improved critical care management, the field has turned its attention to diffuse injury, or PWMI, which is prevalent at alarming frequency in many survivors of premature birth. Noncystic PWMI comprises more than 95\% of brain lesions in preterm infants [134], and epidemiological evidence also indicates the involvement of inflammatory processes.

In normal developing telencephalon, microglia are concentrated at junctional regions of WM internal and external capsule [135]. These microglia clusters are thought to be related to phagocytic events in developing axon bundles. In a study comparing very preterm infants with preterm infants suffering from PWMI, axonal crossroads in the frontal lobe showed greater microglia-macrophage densities and activation in the very preterm, along with lower incidence of astrogliosis [136]. Based on the activation profile of microglia during pregnancy, this further supports the notion that cellular vulnerability may be determined by the age-dependent activation pat- 
tern of microglia, in addition to specific oligodendroglial developmental stage in preterm brains.

Preoligodendrocytes [O4+, myelin basic protein-negative (MBP-); fig. 1] have been shown to be particularly susceptible to free radical attack and excitotoxicity [113]; hence, mechanisms which activate these pathways, such as elevated brain cytokines, are most likely to produce apoptotic death and WM injury in PVL [137]. Despite reports of preoligodendrocyte vulnerability in PVL [138], the numbers of preoligodendrocytes as identified with Olig2 - a cell type-specific transcription factor expressed in cells of the oligodendrocyte lineage - were not found to be significantly different from controls [136], a feature also found in separate studies of preoligodendrocytes in PVL [139]. Both oligodendrocytes and microglia were observed to proliferate in focal and diffuse lesions of PVL, although these differences in cell number did not reach statistical significance in the analyzed samples [139]. This latter finding is unexpected, as activated microglia are significantly increased in PVL. Possible explanations include time point of analysis and other reasons for the increase, such as cell migration from adjacent regions [139]. Nonetheless, these observations indicate that subtle changes in WM may occur without accompanying changes in oligodendrocyte cell number, and the challenge in understanding diffuse and milder forms of PWMI may lie in identifying changes in many other properties of myelination, such as myelin lamellae ultrastructure, myelin protein expression levels and distribution, as well as interaction with other cell types, notably with neuronal axons.

\section{Microglia in PVL}

While it is unclear whether the brain's inflammatory response is secondary to systemic inflammation from infection, or to 'sterile' traumatic injury like hypoxia-ischemia, it was consistently found that the inflammatory response in WM was mediated by resident microglia. Characterization of autopsy brain tissue from PVL cases has revealed not only preferential WM involvement, but also diffuse microglial activation throughout the affected $\mathrm{WM}$, along with protein nitration and lipid peroxidation in premyelinating oligodendrocytes [49]. An abundance of activated microglia has been found in the diffuse component of PVL, with macrophages in the necrotic foci, and without marked presence of activated microglia over the cortex [49]. This analysis, based on markers of activated microglia and astrocytes, showed that the overlying cerebral cortex was spared [49], making PVL a predominantly WM disease. The toxicity of elevated nitric oxide arises from the formation of the protein adduct, nitroty- rosine, a product of macromolecular damage, in the presence of reactive oxygen species. Characterization of the PVL lesions for enzymatic markers of tissue damage revealed a significantly increased density of cells positive for induced NOS (iNOS), which produces nitric oxide from arginine. The iNOS-positive cells were reactive astrocytes and microglia [140], although both of these cell types were not always present together in the lesions. iNOS expression was found in both the focally necrotic and diffuse lesions of PVL. Within the diffuse lesions, while reactive astrocytes were present at all stages of PVL, iNOSpositive CD68+ microglia were predominantly found in acute lesions and not subacute ones. Nitrotyrosine adducts have been identified in PVL in premyelinating oligodendrocytes [49], so that these studies collectively indicate that oligodendrocyte damage in PVL due to peroxynitrite may be mediated by reactive astrocytes as well as activated microglia.

\section{Endotoxin Models}

Studies of maternal infections have shown an association with high incidence of schizophrenia [141]. An increased inflammatory cytokine profile was observed in the serum of mothers at mid-pregnancy who subsequently gave birth to children with developmental delay or autism [142]. The prenatal cytokine hypothesis of schizophrenia is supported by abundant evidence: the involvement of numerous pathogens, such as influenza, rubella, measles, polio, herpes simplex and toxoplasma, indicates that the maternal immune system, through induction of proinflammatory cytokines, can alter early brain development and consequently elevate the risk of schizophrenia and behavioral disorders in the offspring [143]. The cytokine-mediated inflammatory response to infection in both maternal and fetal compartments depends on the stage of gestation. Furthermore, the timing of infection is believed to determine the nature of the abnormality. Midgestational maternal infection results in suppressed exploratory behavior, while late gestational infection gave perseverative (uncontrolled repetitive) behavior implicated in schizophrenia, autism, and obsessive-compulsive disorders [144].

To mimic systemic prenatal bacterial infection, maternal exposure to LPS administered through intraperitoneal injection has been widely used in several animal models of prenatal inflammation. LPS is a major component of the outer membrane of Gram-negative bacteria and is recognized by Toll-like receptor (TLR) 2 and 4 . 
Upon binding to TLR, LPS stimulates the release of proinflammatory cytokines such as IL- $1 \beta$, IL- 6 and TNF- $\alpha$ $[145,146]$.

The fetal immune system is not functionally mature until after mid or late gestation [147], so that the LPS injections in the prenatal model frequently target rodent gestation days 15-16 (mid) or 18.5 (end of murine gestation). Intracervical injections at 15 days of gestation (E15) leads to differential elevation of cytokine levels within the placenta and fetal brain within $24 \mathrm{~h}$ [148], increased cellular apoptosis and cytokine expression in fetal rat brains at E20, followed by decreased 2',3"'-cyclic nucleotide $3^{\prime}$-phosphodiesterase and proteolipid protein (PLP) levels in the corpus callosum at postnatal day 21 (P21) [149]. Activated microglia identified by $\mathrm{Ox} 42$ immunostaining were however not detected at this age, but the fetal immune system was found to participate in the production of cytokines such as IFN- $\gamma$, which was higher within the fetal brain than in the placenta. This mid-gestational LPS model in rats was also reported to produce reductions in communicative behaviors (ultrasonic vocalization) and associative learning (odor-stroke stimulus) at P8 [150]. Similar WM injury was observed with LPS injections at E18 and analyzed at P8 [151]. Strangely, activated microglia were not found to be increased by LPS in this study. However, when intracerebral LPS injections were performed at P5 instead, proinflammatory cytokines were induced, and activated astrocytes and microglia were found [152], in addition to hypomyelination. The reason for the preferential activation of microglia after postnatal LPS is unclear, but the role of cytokines remains consistent. Myelination defects and ventricular enlargement were improved by introduction of IL-1 receptor antagonist, indicating an important role of cytokines in injury [152]. In a mouse model of E18.5 intrauterine inflammation to produce term chorioamnionitis, IL-1 $\beta$ and IL-6, both proinflammatory cytokines, were elevated [153]. This was associated with remodeling in neurons [154]. It was determined that inflammatory conditions were the cause of injury, rather than premature birth per se [154]. Inflammation that was insufficient to induce parturition, but sufficient to activate an immune response in the placenta and fetal brain, was found to result in injury at P7 [155]. In a separate study, chronic subclinical inflammation was shown to lead to WM damage in a neonatal model in which low-dose LPS was administered daily between P3 and P11 [156]. In addition to impaired myelination, gray matter volume was also reduced [156], so that low-level chronic inflammation should also not be overlooked in understanding widespread neurodevelop-

Myelin Development and Microglia in Schizophrenia mental changes. Using a primate LPS model, low-dose endotoxemia instead showed a phenotype of enhanced gray matter and WM volume by MRI, although abnormalities were still observed in tests of prepulse inhibition [157]. This finding suggests that these changes in brain volume may be characteristic of primates, and careful titration of LPS response in various animal species would aid the interpretation of observations of possible underlying mechanisms.

The effect of LPS on oligodendroglia is indirect, as oligodendrocyte damage only occurs in the presence of microglia through TLR4 [158], although cytokines per se may have both direct effects on oligodendroglia. It is also possible that a combination of both direct and secondary injuries through activated microglia and astrocytes contributes to the damage in PVL. Thus, persistent microglial activation results in ongoing and chronic neuroinflammation seen in PVL [112]. Under physiological conditions, astrocytes and microglia support OPC viability and development [159]. However, LPS-activated microglia inhibit OPC proliferation [160] and induce death [161] in two successive waves, first via nitric oxide release, then followed by TNF- $\alpha$ induction and loss of trophic support from the action of insulin-like growth factor 1 (IGF-1) and ciliary neurotrophic factor 1 [161]. In contrast, mature oligodendrocytes are protected by LPS-activated microglia $[108,160]$. These observations demonstrate the selective vulnerability of the immature OPC to LPS- and infectionmediated damage by activated microglia, which supports a developmental origin of inflammatory WM injury.

\section{Maternal or Neonatal Immune Activation with Polyriboinosinic-Polyribocytidilic Acid}

Another animal model that involves the damaging effects of the maternal immune response on the fetus is based on viral infections during pregnancy [162]. This model makes use of maternal exposure to the viral mimetic polyriboinosinic-polyribocytidilic acid [poly(I:C)]. Double-stranded RNA, generated during viral infection as a replication intermediate for single-stranded RNA, or as a by-product of transcription in DNA viruses, is recognized by the pathogen recognition receptor TLR3. Poly(I:C) is a synthetic analog of double-stranded RNA that also binds TLR3 [163] and stimulates the release of proinflammatory cytokines like IL- $1 \beta$, IL- 6 and TNF- $\alpha$ [164-166]. In this mouse model, pregnant dams are exposed to poly(I:C) at a specific gestational stage (e.g. E15 or E17). This causes a wide variety of behavioral, cognitive, 
neurotransmitter and pharmacological abnormalities in adult offspring [167-169]. To address the concern that prenatal exposure to poly(I:C) raised the rate of abortion, Ibi et al. [170] have shown with daily subcutaneous injections of poly(I:C) in the neonate that impairment was still detected in multiple behaviors, such as startle response, social interaction, novel object recognition, and increased anxiety in the open field test [170]. Metabolic disturbance after prenatal poly(I:C) was found to be accompanied by changes in peripheral secretion of the proinflammatory cytokines IL-6, TNF- $\alpha$, IL- 2 and IFN- $\gamma$ [171], lending support that prenatal immune activation by viruses increases the risk of schizophrenia-like abnormalities. In a recent study using poly(I:C) exposure at E9, Juckel et al. [172] showed that microglial cells in the P30 hippocampus and striatum of offspring brains were more numerous and more activated than in controls, indicating that microglial activation likely contributes to long-term damage following maternal infection during embryogenesis.

Although the majority of studies demonstrate neuronal changes after poly(I:C) exposure $[173,174]$, prenatal exposure has been shown to lead to delayed myelination and axonal development in the hippocampus [175]. Both myelin thickness and axon diameter in this region were found to be decreased at P14, but hypomyelination was no longer detected in adulthood. This was distinct from axons in the frontal cortex, where such changes were not observed even at P14 [175]. Furthermore, despite a decrease in MBP expression, there was no significant loss of oligodendrocytes as detected by dual PLP in situ hybridization with Olig2+ immunocytochemistry. It is possible that the mild and highly specific nature of the injury in this study resulted in the lack of difference in the behavior tests in the open field and spatial memory [175]. Nonetheless, the transient decrease in myelin protein levels is reminiscent of neonatal hyperoxia injury (see below) where recovery of MBP levels, accompanied by cellular recovery, appears complete by P15 [176]. In culture, however, poly(I:C) prevents differentiation of OPCs and causes death of oligodendrocytes in enriched cultures [177]. Despite ubiquitous TLR3 expression in preoligodendrocytes, microglia and astrocytes, and the simultaneous activation of both microglia and astrocytes, the toxicity of poly(I:C) to preoligodendrocytes was determined to be indirect, and mediated by microglial production of TNF- $\alpha$ in culture [178]. Since poly(I:C) exposure results in increased activation of microglia [179], similar to LPS, it is likely that activation characteristics between the two stimuli may overlap. Indeed, it was found in cultured BV2 microglia cells that both stimulated the pro- duction of TNF- $\alpha$, IL- 6 , IL-1 $\beta$, IL-1R $\alpha$ and cyclooxygenase 2 [180], although precise patterns of activation may differ. This strongly supports the microglial contribution to developmental WM damage and behavioral deficits.

\section{Animal Models of Hypoxia-Ischemia and Chronic Perinatal Hypoxia}

In addition to pathogen-induced inflammation, other established risk factors which predispose the infant brain to PVL are hypoxia-ischemia (or asphyxia) and hypoxia. Such conditions can occur in association with maternal diabetes, asthma, anemia, or as a consequence of maternal or fetal heart disease [181, 182]. Premature or prolonged labor compromises fetal oxygenation, as the infant has not yet developed a fully functional cerebral blood supply and autoregulatory responses [183]. Furthermore, inadequate gas exchange by poorly developed lungs in premature infants [184] often leads to tissue hypoxia. In experimental models, both pre- and postnatal exposure to hypoxia-ischemia inflict extensive damage to gray matter and WM. Transient uterine artery occlusion in rats, lasting up to $60 \mathrm{~min}$, on gestation day 18 to produce a prenatal hypoxic-ischemic insult leads to persistent loss of oligodendrocytes and neurons by $\mathrm{P} 5$ or $\mathrm{P} 9[185,186]$ that is consistent with observations in survivors of preterm birth with brain damage [187]. To model near-term hypoxicischemic injury using the Rice-Vannucci method and its variants for neonatal rodents [188, 189], hypoxia-ischemia is induced in P7 rat pups by unilateral ligation of the common carotid artery, followed shortly by exposure to systemic hypoxia with $92 \%$ nitrogen $/ 8 \%$ oxygen for up to $3 \mathrm{~h}$. Hypoxia induced with $6 \%$ oxygen following an hour of recovery after ligation of the proximal internal artery has been used to produce WM injury [190, 191]. Hypoxia exposure at $24 \mathrm{~h}$ after ligation produces far less cell loss than at $4 \mathrm{~h}$ [192], so that the broadest spectrum of necrotic injury in multiple brain regions is obtained when ligation is followed immediately by hypoxia. Cerebral blood flow returns to control levels immediately upon transfer to normoxic conditions, but the hyperemia that is typical of reperfusion in adults was reportedly not observed in the immature rat [193]. Younger neonates (P1) have also been used to achieve conditions resembling mid-gestation hypoxia [194]. Even an hour of ischemia by common carotid artery occlusion was sufficient to induce longterm behavioral disturbance in postnatal rats, such as impaired prepulse inhibition of the startle reflex measured 38 days after the injury and locomotor hyperactivity 
[195]. The ischemic damage which produces spontaneous motor hyperactivity and memory impairment in selective tasks has been associated with WM injury accompanied by axonal degeneration [196].

DTI studies show that severe hypoxia-ischemia in both preterm and term neonates damages deep gray matter, with less severe injury to periventricular WM in preterm neonates [197]. Tissue loss that includes cerebral degeneration and corpus callosum injury is associated with chronic deficits in locomotor and spatial memory and learning [198], including the passive avoidance test which assesses fear-induced memory [199]. Hypoxia-ischemia in neonatal mice selectively increased apoptotic cell death in the subventricular zone, a germinal region for neural progenitor cells, and the WM, but not in the striatum. The insult appeared to spare mature oligodendrocytes, although hybridization assays showed rapid and significant reductions in the expression of myelin genes [200]. Instead, the WM loss results from selective death of preoligodendrocytes which would begin to express myelin genes [201]. Despite the increased generation of nascent oligodendrocytes following neonatal hypoxic-ischemic injury [202], the recovery of WM function appears incomplete. The arrest in myelination was due to a failure of maturation of oligodendroglia despite a dramatic expansion of the preoligodendrocyte population (late oligodendrocyte progenitors) [203]. In addition, radial glia became reactive nestin-expressing astrocytes, and an enhanced proliferative activity of astrocytes, NG2+ oligodendrocyte progenitors and RIP-positive oligodendrocytes was observed after injury [204]. This suggests that hypoxia-ischemia induces cortical tissue remodeling, and brings significant changes in cell numbers. In addition to cell necrosis in the corpus callosum, the numbers of both NeuN+ neurons in the cortex and hippocampus were also decreased [205], along with an increase in the total number of cells undergoing apoptotic death [206]. Under these conditions, greater numbers of activated microglia were found [205], whose inhibition with minocycline led to improvement in neurobehavioral function and reduction in WM loss.

While perinatal hypoxia-ischemia produces a range of severe pathologies that overlap with the stroke phenotype, the contribution of hypoxia alone has also been recognized to be very important in causing brain injury and altered neuronal development. A survey of the gene changes reported to be significantly associated with schizophrenia revealed that more than $50 \%$ of these were regulated by hypoxia and expressed in the vasculature [207], indicating a critical role for inadequate oxygen delivery in

Myelin Development and Microglia in Schizophrenia brain injury. After chronic sublethal hypoxia during the first 7-10 days of postnatal life, rodents show temporary $\mathrm{WM}$ reduction and loss of cortical neurons in the weeks following recovery from exposure [208]. However, even after apparent recovery of WM tissue [208], long-lasting neurobehavioral deficits, such as those in working memory, are detected [209]. Tissue loss in the hippocampus occurs at a greater rate in males than females, which may account for sex differences in risk assessment for poor neurodevelopmental outcome [210]. Microglia are active in phagocytosis of debris from degenerating axons and other apoptotic cells in neonatal rodents after hypoxia [211]. Through cytokine release such as TNF- $\alpha$ and IL-1 $\beta$ [212], accompanied by increased susceptibility through elevated TNF-R1 expression in oligodendrocytes in WM [212], microglia are believed to be responsible for early events in the inflammatory response to hypoxic conditions [213], and to contribute to the death of both neurons and oligodendrocytes in the developing brain [214].

Hypoxia-induced loss of myelin-associated Nogo-A increases axonal sprouting and encourages axonal misconnection in the corticospinal tract, corpus callosum and caudate nucleus in the adult [215]. A study of the direct effects of progressive hypoxia on cultured oligodendrocytes showed that synthesis of the major myelin component galactosylceramide, which is an ATP-dependent process, was severely impaired, as newly synthesized ceramide was inhibited from being transported to sites of galactosylation [216]. It is possible that chronic inhibition of this process could lead to eventual death of the cell. Paradoxically, hypoxia was also shown to enhance the generation of MBP+ oligodendrocytes in culture, and to decrease the population of progenitor cells, a process involving regulation of cell cycle regulators p27Kip1 and phospho-cdc2 (cyclin-dependent kinase 1) [217]. This study suggests that low oxygen conditions promote premature maturation of oligodendrocyte progenitor cells, and demonstrate that oligodendrocyte progenitors do respond directly to hypoxia in the absence of inflammatory influences.

\section{Animal Models of Hyperoxia-Induced Perinatal WM Damage}

For preterm infants, premature birth into room air may constitute exposure to relative hyperoxia, with oxygen tensions 3 - to 4 -fold higher than physiological levels in utero [218]. Establishment of neonatal rodent models using $80 \%$ oxygen (i.e. 4 -fold over $21 \%$ oxygen in room air at atmospheric pressure) has facilitated our under- 
standing of the effects of oxygen on the developing brain. In the immature brain of newborn rats, hyperoxia (through exposure to $80 \%$ oxygen) has been found to induce apoptotic neural cell damage [219]. Oligodendrocyte loss was consistently reproduced by exposure to oxygen at P3 and P6, but exposure at P10 did not affect the WM, indicating a specific developmental window of vulnerability [220]. In a mouse model of neonatal hyperoxia in which pups were exposed to $80 \%$ oxygen from P6 through P8, specific early changes to oligodendroglia were shown to include reduced progenitor cell proliferation, modestly increased apoptotic cell death, and delayed maturation of the oligodendroglial lineage within the WM regions [176]. Ultimately, however, the numbers of myelinating oligodendrocyte cells and MBP levels in these mice return to normal levels by P15. Despite the transient nature of cellular hypomyelination, persistent structural alterations in the corpus callosum are nonetheless still detected by DTI at P30, P53 and P60, as indicated by decreased FA and increased radial diffusivity [176, 221].

Consistent with these findings of WM damage, young adult mice previously exposed to hyperoxia showed altered locomotor activity [221] in the motor skill sequence test which reliably detects changes in fine motor ability [222]. This test involves an initial 2-week training period using running wheels with regularly spaced crossbars, followed by a test period using complex wheels with irregularly spaced crossbars. Running velocity is electronically recorded throughout both phases. On training wheels with regularly spaced crossbars, mice that were previously exposed to hyperoxia showed significantly higher maximum and average running velocities, suggesting hyperactivity as previously characterized in the High-Runner mice, a selectively bred mouse strain that is considered a mouse model of ADHD [223]. When subsequently placed on complex running wheels, which demand high levels of central coordination, hyperoxia-treated mice showed a decreased capacity to meet this motor challenge [221]. These activity and motor symptoms are also consistent with those found in survivors of premature birth, who often suffer from ADHD and impaired motor coordination $[224,225]$.

A systematic review by de Kieviet et al. [224] analyzing 10 clinical studies of motor development in former preterm infants at ages 5-15 years found that there is an overall motor impairment in very preterm children (i.e., less than 32 gestational weeks) and very-low-birth-weight children (less than $1,500 \mathrm{~g}$ birth weight) compared with term-born peers. In particular, there is poorer fine motor and gross motor performance in very preterm children and very-low-birth-weight children had poorer outcomes for both fine motor and gross motor subscales [226]. In addition, a strong association of very preterm birth and diagnosis of ADHD through adulthood has been shown in a population-based cohort in Norway documenting a 5 -fold increased risk for ADHD in patients who were born at less than 28 gestational weeks [227]. The clinical symptoms of ADHD children born preterm may be categorized according to either the inattention type of ADHD or the hyperkinetic disorder type including restlessness and poor impulse control $[228,229]$. Motor symptoms and ADHD symptoms tend to co-occur in low-birth-weight infants [230], with up to half of the children with ADHD displaying motor deficiencies [231]. While the phenomenon of attention is considered by many researchers as an executive function of the prefrontal cortex, whose dysfunction is evident in patients with schizophrenia, schizophrenia is generally not believed to be a sequela of ADHD. Nonetheless, a recent study reporting ADHD symptoms in adolescents presenting as a precursor of adult psychosis suggests that the rare possibility of developing schizophrenia spectrum disorders from ADHD-like symptoms should not be dismissed or overlooked [232].

It is however presently unknown whether this rodent model of neonatal hyperoxia-induced WM injury produces behavior phenotypes closely related to schizophrenia. The DISC1 mouse mutant was characterized using behavior tests, such as prepulse or latent inhibition, forced swim test and tail suspension test [233], which measure sensorimotor gating in anxiety-like behaviors, response to stress, and which detect depression-like responses. The rodent hyperoxia model should be further tested for many behavioral parameters. As both hypoxia and hyperoxia cause perinatal WM damage and decreased WM FA in rodents, they could both potentially increase risk of schizophrenia; it would be important to compare the lesions generated acutely by these distinct, yet related, injury paradigms at the neurobiological level, along with studies of behavioral changes throughout postnatal development to determine long-term functional impact.

In cell cultures of immature oligodendrocytes, $80 \%$ oxygen directly causes massive cell death which can be blocked by pan-caspase inhibitors [234]. Hyperoxia also activated pathways downstream of the FAS receptor, indicating apoptotic cell death as a major mechanism of neural cell damage in vitro. Consistent with the beneficial effects of estradiol on oligodendrocyte survival in culture and in downregulating inflammation after spinal cord in- 
jury in rats $[235,236]$, the administration of estrogen protects immature oligodendroglia against hyperoxia-induced cell damage in a dose-dependent manner [237]. While diverse cellular mechanisms are likely to contribute to damage, Schmitz et al. [176] have recently documented that glutamate transport in WM is compromised after hyperoxia, and cultured astrocytes exposed to hyperoxia have a decreased ability to protect OPCs against glutamate toxicity. Hence, hyperoxia in neonatal rodents produces features of brain pathology frequently found in preterm infants, and has proven to be a useful model in the understanding of the causes and consequences of WM injury in the developing brain. However, it is perhaps still too early to determine at what frequency infants who were born prematurely eventually developed psychosis, as studies of this nature are still in progress; nonetheless, according to a recent analysis of individuals born around 1974, the risk of psychiatric disorder was clearly found to increase with the degree of prematurity [238].

Following hyperoxia exposure in the immature brain, inflammatory reactions have been reported to involve upregulation of proinflammatory cytokines IL- $1 \beta$ and IL-18 $[132,133]$. Administration of recombinant human IL18-binding protein, which is a specific inhibitor of IL-18, attenuated brain injury caused by hyperoxia. Mice deficient in IL-1 receptor-associated kinase 4, which is pivotal for both IL- $1 \beta$ and IL-18 signal transduction, were protected against oxygen-mediated neurotoxicity [239]. In our lab, measurement of iNOS and TNF- $\alpha$ in neonatal rat brains after acute exposure to hyperoxia at P6 for up to $24 \mathrm{~h}$ showed a remarkable 28 -fold increase in iNOS and an 8-fold increase in TNF- $\alpha$ gene expression after only 3 $\mathrm{h}$ of hyperoxia (unpublished data). Taken together, oxygen toxicity in the immature brain is associated with inflammation involving various cytokines and mediators. Whether the origin of this inflammatory response is to be found in microglia, astroglia or infiltrating cells, and whether it is of a primary nature or a secondary response to oligodendroglial cell damage has yet to be clarified. Nevertheless, promising strategies for neuroprotective intervention by enhancing anti-inflammatory properties, such as with erythropoietin (EPO) and minocycline (see below), may benefit the premature infant.

\section{Cytokine-Mediated Models of WM Damage}

Chronic schizophrenia has previously been associated with inflammatory conditions, but it was only recently found that first-episode psychosis patients showed ele-

Myelin Development and Microglia in Schizophrenia vated levels of IL- $1 \alpha$, IL-1 $\beta$ and TNF compared with healthy controls [240]. An attempt at biochemical staging between early and late chronicity however failed to establish differences in inflammatory and oxidative stress markers [241], suggesting that such changes may occur earlier, i.e. preceding onset of disease. While many animal-based studies have shown an association between inflammation and perinatal brain injury, the clinical evidence offers stronger support in preterm infants and subjects with PVL that elevated proinflammatory cytokine levels play an important role in WM damage. It was noted that IL- $1 \beta$ was an important feature of white matter pathology [242], while IL-8 was determined as a useful predictor of WM injury in subjects with sepsis [243], while another study utilizing ultrasound assessment of WM concluded that cytokine-receptor interactions were more important [244]. IL-1 $\beta$ was localized with matrix metalloproteinase 9, an IL-1-induced neurotoxic mediator, in microglia/macrophages in cerebral areas [242], indicating that the IL-1 system may be involved in WM damage. In another study of premature infants utilizing ultrasound assessment of WM, no direct association between individual plasma cytokine and soluble receptor levels and WM injury could be definitively established [244]. However, based on mathematical interactive analysis using bioactive cytokine models consisting of variables calculated from cytokine/receptor equations for TNF, IL- $1 \beta$ and IL- 6 , the authors of this study concluded that cytokine-receptor interactions were more reliable predictors of injury than individual plasma levels [244].

Indeed, systemic inflammation in a neonatal mouse model using daily intraperitoneal injections of IL- $1 \beta$ over 5 days resulted in lasting hypomyelination. This was characterized by an increased number of unmyelinated axons and decreased diameter of myelinated axons [245], which could be attributed, at least in part, to a block in the maturation of OPCs. This is associated with reduced WM FA and memory deficits [245]. Intracerebral injections of IL-1 $\beta$ in neonatal rats also produce a reduction in the number of developing oligodendrocytes $24 \mathrm{~h}$ after injection. Injection of TNF- $\alpha$ did not have the same effect, indicating that direct action of IL- $1 \beta$ impairs myelination [246]. IL- $1 \beta$ was found not to be directly toxic to oligodendrocytes in pure culture, but causes apoptosis in the presence of astrocytes and microglia [247]. The toxicity was attenuated by the AMPA receptor antagonist NBQX, which indicates the involvement of glutamate excitotoxicity mediated by microglia [248]. In addition, cytokineinduced loss of glutamate homeostasis by astrocytes [249] also contributes to excitotoxicity to oligodendroglia. 


\section{Animal Models of Demyelination}

Although not considered directly relevant to studies of neural development, demyelination models are included because of behavioral features that are associated with adult WM lesions. Cuprizone or biscyclohexanone oxalyldihydrazone is a copper chelator that selectively damages oligodendrocytes and is widely used in mouse models of adult demyelination. Microglia have an important role in the pathogenesis and progression of multiple sclerosis, and studies have suggested that tissue changes and damage may also occur in the absence of lymphocyte infiltration [250]. Chemical models of damage such as cuprizone are generally considered less effective than an autoimmune model to recapitulate multiple sclerosis, as these lack the leukocyte infiltration that is characteristic of the human disease [251]. However, it remains immensely useful as a tool to analyze cellular responses in mechanisms of WM damage and repair without the influence of the periphery. By extending the period of exposure from 6 to 12 weeks, the extent of spontaneous cellular repair can be greatly reduced or prevented. In addition to motor deficits [222, 252], cuprizone has also been shown to impair working memory function, decrease social interaction $[253,254]$ and to alter prepulse inhibition of acoustic startle, a physiological property associated with schizophrenia [254]. Although cuprizone-induced demyelination in the brain is widespread, clear regional differences are observed [255], and analysis of the hippocampus and neocortex in this model indicates that damage in gray matter structures occurs over a different time course than in WM [256], which implicates differences in pathological mechanisms. Furthermore, lasting deficiencies in working memory were observed even after remyelination following cuprizone exposure in younger adolescent mice [253], and social interaction was impaired compared with exposure in adult mice, suggesting that the cellular and immune response to cuprizone damage may also be heightened in the immature brain, which could potentially affect its capacity for repair.

In the adult, cuprizone not only stimulated microglia to proliferate locally but also recruited microglia into areas of demyelination. The microglial expansion exceeded that of infiltrating macrophages and T cells, and the $\mathrm{T}$ cells did not appear to be activated [257]. A role for microglia in indirect cuprizone-induced damage was suggested in culture, in which neither cuprizone nor proinflammatory (TNF- $\alpha /$ IFN- $\gamma$ ) cytokines alone caused oligodendroglial cell death, but instead showed a small increase in the percentage of proliferating cells in the $S$ phase [258]. The combination of cuprizone with cytokines, however, proved to be toxic to primary oligodendroglia. Taken together with the observation that cuprizone-induced demyelination is attenuated by minocycline, which also reduced Ox42/CD11b-expressing microglia, these studies support the idea that the effects of cuprizone on oligodendroglia may be mediated at least in part through cytokine secretion by activated microglia [258]. In other studies, minocycline also showed beneficial effects in attenuating the myelin damage in both cortex and corpus callosum after 4-6 weeks of cuprizone [259]. When administered simultaneously with cuprizone, minocycline improved motor coordination in the beam walking test, although the differential protection of various myelin-specific proteins was partial and regiondependent. Notably in this study, spontaneous re-expression of the myelin proteins PLP, MBP and 2',3'-cyclic nucleotide $3^{\prime}$-phosphodiesterase was demonstrated in the corpus callosum without minocycline, but in the cortex, progressive damage by cuprizone continued. Minocycline also did not affect OPC numbers or the extent of astrogliosis [259], suggesting that direct protection of these cells by minocycline was less likely. Besides minocycline, modulation with antipsychotic drugs such as quetiapine and clozapine [260] has also shown enhanced protection or cellular repair in the demyelinated lesions using simultaneous treatment with cuprizone [260] or after cuprizone withdrawal [261]. Importantly, quetiapine and clozapine improved cognitive function and blocked abnormal social interaction in this model $[260,261]$. The action of quetiapine may be anti-inflammatory, as with minocycline, although specific effects on microglia in this demyelination model are presently unknown.

\section{Treatment with Anti-Inflammatory, Antioxidant and Antipsychotic Agents - Observations in WM Injury}

Given the body of evidence for the detrimental effects of microglial activation in perinatal WM injury, along with studies showing microglia-mediated toxicity to OPCs in vitro, much hope has thus been placed upon anti-inflammatory and antioxidant agents to alleviate the damage to developing oligodendroglia. Based on studies that showed not only a reduced anti-inflammatory capacity, but also a reduced response to anti-inflammatory stimuli in term and preterm infants [262], cytokines or pharmacological agents which enhance anti-inflammatory activity would be expected to improve neurological outcome in injury models. In fact, a study performed in 
preterm infants found a correlation between homozygosity for an allele for high expression of IL-10 and a reduced risk of disorders of prematurity [263]. In the following paragraphs, recent findings are summarized which describe anti-inflammatory approaches to intervention in experimental models of developmental WM injury.

The anti-inflammatory cytokine IL-10 is known to inhibit both IL- 6 and TNF- $\alpha$ production in LPS-stimulated cells of the THP-1 human leukemic monocyte line and a rat alveolar macrophage line [264]. Consistent with these results, the application of IL-10 in neonatal mice protected neonatal mice from excitotoxic brain injury [265]. IL-10 was also protective in maternal Escherichia-coli-induced WM injury [266, 267]. Accordingly, sensorimotor impairment associated with the damage, such as delayed righting, startle response and eye opening, was prevented with IL-10 combined with ceftriaxone [268]. Ceftriaxone is an antibiotic which increases glutamate transporter activity [269] and which has demonstrated neuroprotective properties [270]. In this study, neonatal infection with E. coli also led to long-term memory deficits in P75 adult rats. The combined IL-10/ceftriaxone treatment lowered IL-1 $\beta$ levels in infant rats at P8, prevented ramified microglial morphology, increased locomotor activity and offered some protection against changes in long-term potentiation and the impairment of learning and memory skills. In support of an important role for IL- $1 \beta$, treatment with an IL-1 receptor antagonist improved fetal mortality, offspring WM structure and motor behavior in a maternal LPS model [271]. The importance of blocking the effects of IL- 1 is further supported by the application of a-phenyl-N-tert-butylnitrone, a free radical scavenger, in providing long-lasting protection against IL-1 $\beta$-induced brain injury. IL- $1 \beta$ exposure causes ventricular enlargement, loss of mature oligodendrocytes, impaired myelination, and motor deficits, all of which were attenuated by inclusion of $\alpha$-phenyl-N-tertbutyl-nitrone [272]. The protection was not restricted to the WM, as IL-1-induced pathology included axonal and dendritic damage, which were also ameliorated by a-phenyl-N-tert-butyl-nitrone treatment [272].

EPO is emerging as an effective protective agent, despite concerns of complication arising from its erythropoietic effects. EPO has been shown to act directly on neural cells in culture and offers protection in animal models of injury [273]. In a rat model of hypoxia-ischemia by transient uterine artery occlusion, neonatal administration of recombinant EPO was shown to improve the survival of oligodendrocytes and GABAergic neurons, restore myelin production and motor performance in adult rats [185]. Notably, seizure threshold after injury was raised to nor-

Myelin Development and Microglia in Schizophrenia mal levels with EPO treatment, indicating that the prenatal trauma-induced changes in neuronal development and circuit formation that lead to epilepsy are not irreversible [185]. In a late gestation LPS model, two paradigms - maternal and postnatal EPO treatment - both reduced the levels of IL- $1 \beta$, TNF- $\alpha$ and IL- 6 , accompanied by attenuation of apoptotic cells in the periventricular WM [274]. However, maternal EPO was more effective in protecting the WM from loss of myelin-producing cells. This indicates that the majority of the reversible damage occurs temporally closer to the initiation of the infection, and thus offers a viable treatment option.

Minocycline is a widely used tetracycline derivative that also suppresses the activity of inflammatory mediators independently of its antibiotic activity. It attenuates LPS-induced neuroinflammation and behavioral changes [275], as well as enhances the survival and growth of neural stem cells after ischemic stroke in adult rats [276]. Minocycline has also been shown to provide protection against gray matter and WM damage from insults such as neonatal hypoxia-ischemia $[205,277]$ and LPS exposure [278]. Minocycline promoted remyelination in culture after IFN- $\gamma$ and LPS demyelination, indicating that attenuation of microglial activity supports myelin repair by enhancing the maturation of oligodendrocyte progenitor cells [279]. Recently, a direct protective effect of minocycline on purified oligodendrocyte progenitors under oxygen-glucose deprivation stress (an in vitro model of hypoxic-ischemic stress) has been demonstrated [280], which was associated with increased expression of superoxide dismutase in oligodendroglial cells, leading to reduced free radical toxicity and increased cell survival. In support of increasing clinical application, patients with schizophrenia have shown improvement after treatment with minocycline as adjunctive therapy to antipsychotics [281]. In a recent case study of a patient on such therapy, improvement of positive symptoms was accompanied by minocycline-induced changes in cerebral blood flow. Neuroimaging of cerebral blood flow by brain SPECT scans showed hyperperfusion in the posterior cingulate gyrus that was reduced after minocycline treatment [282]. As mentioned previously, the mechanism of neuroprotection by minocycline is not well understood; it has been proposed that minocycline may be a modulator of NMDA-R signaling via p38 or PI3k/Akt pathways [283], or a positive modulator of glutamate GluR1 receptor subunits, which could potentiate the action of antipsychotic drugs [284]. Regardless of its mode of action on glutamatergic transmission, these case studies show that intervention with minocycline appears to remain effective after 
the presentation of clinical symptoms, which offers clear advantages over other potential experimental treatments.

Steroids have long been the mainstay of anti-inflammatory treatments. Cortisol is known to repress LPS-induced nitric oxide production and TNF release from microglia [285]. Ameboid microglial cells are depleted following glucocorticoid injection, and the remaining microglia became ramified, indicating enhanced maturation [286]. Adult microglia express transcripts for glucocorticoid, mineralocorticoid receptors and estrogen receptor alpha, and it is believed that LPS challenge downregulates steroid hormone receptors to suppress the anti-inflammatory actions of endogenous steroid hormones, leading to sustained activation of microglia [287]. Changes in maternal corticosterone levels can also affect microglial properties in newborn pups [288]. Pregnant rat dams subjected to daily forced swim test showed elevated corticosterone levels at gestation day E20, and analysis of their P1 pups revealed a reduction in the number of ameboid or immature microglia, accompanied by an increase in ramified microglia, indicating accelerated microglial differentiation compared with pups from unstressed dams [288]. In culture, corticosteroids were shown to reverse the inhibition of oligodendrocyte development imposed by a combination of the proinflammatory cytokines IFN- $\gamma$ and TNF- $\alpha$, thus improving survival and maturation [289]. The synthetic corticosteroids dexamethasone and betamethasone were also found to protect the WM from neonatal LPS exposure, attenuating many LPS-induced behavioral deficits, e.g. rearing, beam walking, learning and elevated plus maze [290]. However, locomotion and stereotypic movement dysfunction were differentially affected, and weight loss was not prevented by either drug. This study suggests that the action of corticosteroids offers some benefit in protection against brain damage [290]. However, the benefits do not convincingly outweigh the dangers of toxicity, as indicated by the potential for adverse effects [290], including hyperglycemia and hypertension. In fact, postnatal administration of dexamethasone to preterm infants for the treatment of lung disorder leads to impaired neuromotor and cognitive function in school [291]. For this reason, the use of dexamethasone is generally not encouraged in prenatal medicine [292, 293].

Results from MRI studies suggest that long-term administration of the antipsychotic drug risperidone has a positive impact on WM volume of the frontal lobe in schizophrenic patients [294]. Risperidone has been shown to prevent microglial activation, inhibiting iNOS, IL- $1 \beta$, TNF and IL- 6 production by IFN- $\gamma$-stimulated mi- croglia [295] more effectively than haloperidol. As with risperidone, other atypical antipsychotics like perospirone, quetiapine and ziprasidone are effective against IFN- $\gamma$-induced activation of microglia [296]. After neonatal hypoxia in rats, clozapine was shown to block the deficit in prepulse inhibition [297], although specific effects on microglial activation were not analyzed in this model. A significant $25 \%$ volume increase of the anterior internal capsule has been found in a small study on schizophrenia patients after 1 year of constant treatment with olanzapine [298], demonstrating the importance of protecting WM structures in treatment. In contrast, negative effects of haloperidol treatment on oligodendroglial gene expression [299] were found in mice, and decreased cell numbers of astroglia and oligodendroglia have been reported in response to both haloperidol and olanzapine in healthy macaque monkeys [300]. Given the current evidence, the atypical antipsychotic agents show overall advantages over haloperidol in reducing WM tissue damage and some functional deficits in the cuprizone-induced injury, but mixed results may complicate interpretation about drug efficacy in distinct paradigms of experimental WM lesion [301].

Besides anti-inflammatory agents, the growth factor IGF has been used to alleviate WM damage from LPS and hypoxia-ischemia. Although intranasal IGF does not affect the production of cytokines IL- $1 \beta$ and TNF- $\alpha$ after LPS exposure, it nevertheless attenuated the WM injury and also improved some behavioral deficits [302]. It is highly likely that the route of administration and dose determines the outcome of IGF treatment, as it has been shown to produce paradoxical effects on LPS injury [303]. Another growth factor, EGF, whose activity maintains the neural progenitor population in the adult rodent subventricular zone, has been shown to have profound effects in protecting the adult WM from the effects of chemical demyelination in the mouse corpus callosum [304]. Although it is unknown how inflammatory mediators are affected by EGF receptor activity, based on these findings, it would not be unreasonable to predict that the developing brain may also benefit from enhancing neural progenitor function with growth factors after perinatal WM injury.

\section{Closing Comments}

In summary, it has become clear that compromised WM function is an important property which underlies sensorimotor and cognitive impairment in schizophre- 
nia, and that abnormal immune activation plays a role in disrupting the development of WM structures. Targeting microglia activation in neurodevelopmental WM disorders and schizophrenia is showing promising results in improving the preservation of oligodendrocyte survival, progenitor maturation, myelination, WM integrity and attenuating behavioral deficits in a number of animal models of perinatal hypoxic and inflammatory damage. No potential pharmacological treatments are without caveats, as activated microglia participate in both damage and repair, and at present, many current approaches targeting inflammatory WM damage may be better understood in adult disease than in the developmental setting [305]. Furthermore, modulating the inflammatory process may represent only a part of the strategy for intervention, since other protective measures, such as trophic/ growth factor supplementation and stem cell manipulation, contribute to the prevention of lasting damage at various stages of lesion progression. As advancements are being made in determining the risk factors, high-risk criteria and detection of the onset of schizophrenia, and safer preventative and therapeutic approaches may be designed and implemented at stages deemed most efficacious during brain development.

\section{Acknowledgements}

We wish to thank Dr. Vittorio Gallo, Center for Neuroscience Research, Children's Research Institute, for support and discussion, Dr. Cynthia deBoy, Trinity College, Washington DC, for discussion, and Dr. Jonathan Ritter, Center for Neuroscience Research, Children's Research Institute, for providing artwork. L.J.C. receives support from the National Multiple Sclerosis Society RG3954A1/2, and from NINDS R01NS056427 and 1R21NS078731 (with Dr. Gallo). T.S. is supported by Förderverein für Frühgeborene an der Charité e.V.

\section{References}

1 Koch K, Schultz CC, Wagner G, Schachtzabel C, Reichenbach JR, Sauer H, Schlosser RG: Disrupted white matter connectivity is associated with reduced cortical thickness in the cingulate cortex in schizophrenia. Cortex 2012, E-pub ahead of print.

-2 Mandl RC, Rais M, van Baal GC, van Haren NE, Cahn W, Kahn RS, Hulshoff Pol HE: Altered white matter connectivity in nevermedicated patients with schizophrenia. Hum Brain Mapp 2012, E-pub ahead of print.

-3 Friston KJ: Functional and effective connectivity in neuroimaging: a synthesis. Hum Brain Mapp 1994;2:56-78.

-4 Thaker GK: Neurophysiological endophenotypes across bipolar and schizophrenia psychosis. Schizophr Bull 2008;34:760-773.

5 Fornito A, Yoon J, Zalesky A, Bullmore ET, Carter CS: General and specific functional connectivity disturbances in first-episode schizophrenia during cognitive control performance. Biol Psychiatry 2011;70:64-72.

-6 Skranes J, Lohaugen GC, Martinussen M, Indredavik MS, Dale AM, Haraldseth O, Vangberg TR, Brubakk AM: White matter abnormalities and executive function in children with very low birth weight. NeuroReport 2009; 20:263-266.

-7 Jacobs HI, Leritz EC, Williams VJ, Van Boxtel MP, Elst WV, Jolles J, Verhey FR, McGlinchey RE, Milberg WP, Salat DH: Association between white matter microstructure, executive functions, and processing speed in older adults: the impact of vascular health. Hum Brain Mapp 2013;34:77-95.
8 Agius M, Goh C, Ulhaq S, McGorry P: The staging model in schizophrenia, and its clinical implications. Psychiatr Danub 2010;22: 211-220.

-9 Fusar-Poli P, Bonoldi I, Yung AR, Borgwardt S, Kempton MJ, Valmaggia L, Barale F, Caverzasi E, McGuire P: Predicting psychosis: meta-analysis of transition outcomes in individuals at high clinical risk. Arch Gen Psychiatry 2012;69:220-229.

10 Fusar-Poli P, Bechdolf A, Taylor M: At risk for schizophrenic or affective psychosis? A meta-analysis of DSM/ICD diagnostic outcomes in individuals at high clinical risk. Schizophr Bull 2012, in press.

-11 Abrams DJ, Rojas DC, Arciniegas DB: Is schizoaffective disorder a distinct categorical diagnosis? A critical review of the literature. Neuropsychiatr Dis Treat 2008;4:1089-1109.

12 Fusar-Poli P, Borgwardt S, Bechdolf A: The psychosis high-risk state: a comprehensive state-of-the-art review. Arch Gen Psychiatry 2012;19:1-14

13 Fusar-Poli P, Radua J, McGuire P, Borgwardt $S$ : Neuroanatomical maps of psychosis onset: voxel-wise meta-analysis of antipsychotic-naive VBM studies. Schizophr Bull 2012;38: 1297-1307.

14 Fusar-Poli P, Meyer-Lindenberg A: Striatal presynaptic dopamine in schizophrenia. 2 . Meta-analysis of $\left[{ }^{18} \mathrm{~F} /{ }^{11} \mathrm{C}\right]$-DOPA PET studies. Schizophr Bull 2013;39:33-42.

15 Smieskova R, Fusar-Poli P, Allen P, Bendfeldt K, Stieglitz RD, Drewe J, Radue EW, McGuire PK, Riecher-Rossler A, Borgwardt SJ: Neuroimaging predictors of transition to psychosis
- A systematic review and meta-analysis. Neurosci Biobehav Rev 2010;34:1207-1222.

16 Fiedorowicz JG, Epping EA, Flaum M: Toward defining schizophrenia as a more useful clinical concept. Curr Psychiatry Rep 2008; 10 : 344-351.

17 Fusar-Poli P, Yung AR: Should attenuated psychosis syndrome be included in DSM-5? Lancet 2012;379:591-592.

18 Preti A, Cella M: Randomized-controlled trials in people at ultra high risk of psychosis: a review of treatment effectiveness. Schizophr Res 2010;123:30-36.

19 Harrison PJ: The neuropathology of schizophrenia: a critical review of the data and their interpretation. Brain 1999;122:593-624.

20 van Haren NEM, Hulshoff Pol HE, Schnack HG, Cahn W, Brans R, Carati I, Rais M, Kahn RS: Progressive brain volume loss in schizophrenia over the course of the illness: evidence of maturational abnormalities in early adulthood. Biol Psychiatry 2008;63:106-113.

-21 Shenton ME, Dickey CC, Frumin M, McCarley RW: A review of MRI findings in schizophrenia. Schizophr Res 2001;49:1-52.

22 Weinberger RD, Marenco S: Schizophrenia as a neurodevelpmental disorder; in Hirsch SR, Weinberger DR (eds): Schizophrenia. London, Blackwell Publishing, 2003, pp 326-348.

23 Niznikiewicz MA, Kubicki M, Shenton ME: Recent structural and functional imaging findings in schizophrenia. Curr Opin Psychiatry 2003; 16:123-148.

24 Yin DM, Chen YJ, Sathyamurthy A, Xiong WC, Mei L: Synaptic dysfunction in schizophrenia. Adv Exp Med Biol 2012;970:493-516. 
25 Pantelis C, Velakoulis D, McGorry PD, Wood SJ, Suckling J, Phillips LJ, Yung AR, Bullmore ET, Brewer W, Soulsby B, Desmond P, McGuire PK: Neuroanatomical abnormalities before and after onset of psychosis: a crosssectional and longitudinal mri comparison. Lancet 2003;361:281-288.

26 Weinburger DR: Implications of normal brain development for the pathogenesis of schizophrenia. Arch Gen Psychiatry 1987;44: 660-669.

27 Keunen K, Kersbergen KJ, Groenendaal F, Isgum I, de Vries LS, Benders MJ: Brain tissue volumes in preterm infants: prematurity, perinatal risk factors and neurodevelopmental outcome: a systematic review. J Matern Fetal Neonatal Med 2012;25:89-100.

-28 Inder TE, Huppi PS, Warfield S, Kikinis R, Zientara GP, Barnes PD, Jolesz FA, Volpe JJ: Periventricular white matter injury in the premature infant is followed by reduced cerebral cortical gray matter volume at term. Ann Neurol 1999;46:755-760.

-29 Takahashi N, Sakurai T, Davis KL, Buxbaum JD: Linking oligodendrocyte and myelin dysfunction to neurocircuitry abnormalities in schizophrenia. Prog Neurobiol 2011;93:13-24.

- 30 Uranova NA, Vostrikov VM, Orlovskaya DD, Rachmanova VI: Oligodendroglial density in the prefrontal cortex in schizophrenia and mood disorders: a study from the Stanley Neuropathology Consortium. Schizophr Res 2004;67:269-275.

31 Uranova NA, Vostrikov VM, Vikhreva OV, Zimina IS, Kolomeets NS, Orlovkaya DD: The role of oligodendrocyte pathology in schizophrenia. Int J Neuropsychopharmacol 2007;10:537-545.

- 32 Mitkus SN, Hyde TM, Vakkalanka R, Kolachana B, Weinberger DR, Kleinman JE, Lipska BK: Expression of oligodendrocyte-associated genes in dorsolateral prefrontal cortex of patients with schizophrenia. Schizophr Res 2008;98:129-138.

-33 Hakak Y, Walker JR, Li C, Wong WH, Davis KL, Buxbaum JD, Haroutunian V, Fienberg AA: Genome-wide expression analysis reveals dysregulation of myelination-related genes in chronic schizophrenia. Proc Natl Acad Sci USA 2001;98:4746-4751.

- 34 Cui L, Chen Z, Deng W, Huang X, Li M, Ma $X$, Huang C, Jiang L, Wang Y, Wang Q, Collier DA, Gong Q, Li T: Assessment of white matter abnormalities in paranoid schizophrenia and bipolar mania patients. Psychiatry Res 2011;194:347-353.

- 35 Schmitt A, Hasan A, Gruber O, Falkai P: Schizophrenia as a disorder of disconnectivity. Eur Arch Psychiatry Clin Neurosci 2011; 261:S150-S154.

- 36 Whitford TJ, Kubicki M, Schneiderman JS, O'Donnell LJ, King R, Alvarado JL, Khan U, Markant D, Nestor PG, Niznikiewicz M, McCarley RW, Westin CF, Shenton ME: Corpus callosum abnormalities and their association with psychotic symptoms in patients with schizophrenia. Biol Psychiatry 2010;68:70-77.
7 Abdul-Rahman MF, Qiu A, Sim K: Regionally specific white matter disruptions of fornix and cingulum in schizophrenia. PloS One 2011;6:e18652

38 Walther S, Federspeil A, Horn A, Razavi N, Wiest R, Dierks T, Strik W, Muller TJ: Alterations of white matter integrity related to motor activity in schizophrenia. Neurobiol Dis 2011;42:276-283.

39 Wilmsmeier A, Ohrmann P, Suslow T, Siegmund A, Koelkebeck K, Rothermunct M, Kugel H, Arolt V, Bauer J, Pedersen A: Neural correlates of set-shifting: decomposing executive functions in schizophrenia. J Psychiatry Neurosci 2010;35:321-329.

40 Witthaus H, Brune M, Kaufmann C, Bohner G, Ozgurdal S, Budlowski Y, Heinz A, Klingebiel R, Juckel G: White matter abnormalities in subjects at ultra high-risk for schizophrenia and first-episode schizophrenic patients. Schizophr Res 2008;102:141-149.

41 Carletti F, Woolley JB, Bhattacharyya S, Perez-Iglesias R, Fusar-Poli P, Valmaggia L, Broome MR, Bramon E, Johns L, Giampietro V, Williams SCR, Barker GJ, McGuire PK: Alterations in white matter evident before the onset of psychosis. Schizophr Bull 2012;38: 1170-11793.

42 Walterfang M, Yung A, Wood AG, Reutens DC, Phillips L, Wood SJ, Chen J, Velakoulis D, McGorry PD, Pantelis C: Corpus callosum shape alterations in individuals prior to the onset of psychosis. Schizophr Res 2008;103: $1-10$.

43 Ziermans TB, Schothorst PF, Schnack HG, Koolschijn PC, Kahn RS, van Engeland H, Durston S: Progressive structural brain changes during development of pscyhosis. Schizophr Bull 2012;38:519-530.

44 Dean JM, Moravec MD, Grafe M, Abend N, Ren J, Gong X, Volpe JJ, Jensen FE, Hohimer AR, Back SA: Strain-specific differences in perinatal rodent oligodendrocyte lineage progression and its correlation with human. Dev Neurosci 2011;33:251-260.

45 Lu QR, Yuk D-I, Alberta JA, Zhu Z, Pawlitzky I, Chan J, McMahon AP, Stiles CD, Rowitch DH: Sonic hedgehog-regulated oligodendrocyte lineage genes encoding bHLH proteins in the mammalian central nervous system. Neuron 2000;25:317-329.

46 Sun T, Echelard Y, Lu R, Yuk D-I, Kaing S, Stiles CD, Rowitch DH: Olig bHLH proteins interact with homeodomain proteins to regulate cell fate acquisition in progenitors of the ventral neural tube. Curr Biol 2001;11:14131420 .

47 Copray S, Balasubramaniyan V, Levenga J, Bruijn JE, Liem R, Boddeke E: Olig2 overexpression induces the in vitro differentiation of neural stem cells into mature oligodendrocytes. Stem Cells 2006;24:1001-1010.

48 Prata DP, Kanaan RA, Barker GJ, Shergill S, Woolley J, Georgieva L, Picchioni MM, Kravariti $\mathrm{E}$, Walshe $\mathrm{M}$, Allin $\mathrm{M}$, Toulpoulou $\mathrm{T}$, Bramon E, McDonald C, Giampietro V, Murray $\mathrm{RM}$, Brammer $\mathrm{M}$, O’Donovan $\mathrm{M}$, Mc-
Guire P: Risk variant of oligodendrocyte lineage transcription factor 2 is associated with reduced white matter integrity. Hum Brain Mapp 2012, E-pub ahead of print.

49 Haynes RL, Folkerth RD, Keefe RJ, Sung I, Swzeda LI, Rosenberg PA, Volpe JJ, Kinney HC: Nitrosative and oxidative injury to premyelinating oligodendrocytes in periventricular leukomalacia. J Neuropathol Exp Neurol 2003;62:441-450.

50 Back SA, Luo NL, Mallinson RA, O’Malley JP, Wallen LD, Frei B, Morrow JD, Petito CK, Roberts JCT, Murdoch GH, Montine TJ: Selective vulnerability of preterm white matter to oxidative damage defined by F2-isoprostanes. Ann Neurol 2005;58:108-120.

51 Katsel P, Davis KL, Li C, Tan W, Greenstein E, Hoffman LBK, Haroutunian V: Abnormal indices of cell cycle activity in schizophrenia and their potential association with oligodendrocytes. Neuropsychopharmacology 2008; 33:2993-3009.

52 Kerns D, Vong GS, Barley K, Dracheva S, Katsel P, Casaccia P, Haroutunian V, Byne W: Gene expression abnormalities and oligodendrocyte deficits in the internal capsule in schizophrenia. Schizophr Res 2010;120:150158.

53 Fan Y, Abrahamsen G, McGrath JJ, MackaySim A: Altered cell cycle dynamics in schizophrenia. Biol Psychiatry 2012;71:129-135.

54 Brown AS, Bottiglieri T, Schaefer CA, Quesenberry CPJ, Liu L, Bresnahan M, Susser ES: Elevated prenatal homocysteine levels as a risk factor for schizophrenia. Arch Gen Pscyhiatry 2007;64:31-39.

55 Khandaker GM, Zimbron J, Lewis G, Jones PB: Prenatal maternal infection, neurodevelopment and adult schizophrenia: a systematic review of population-based studies. Psychol Med 2013;43:239-257.

56 Brown AS: Prenatal infection as a risk factor for schizophrenia. Schizophr Bull 2006;32: 200-202.

57 Avila MT, Sherr J, Valentine LE, Blaxton TA, Thaker GK: Neurodevelopmental interactions conferring risk for schizophrenia: a study of dermatoglyphic markers in patients and relatives. Schizophr Bull 2003;29:595605.

58 Mrad A, Mechri A, Slama H, Mokni S, Letaief M, Gha L: Correlations between obstetric complications and neurological soft signs in Tunisian patients with schizophrenia. Psychiatry Clin Neurosci 2010;64:645-648.

59 Kendell RE, Juszczack E, Cole SK: Obstetric complications and schizophrenia: a casecontrol study based on standardised obstetric records. Br J Psychiatry 1996;168:556561

60 Jones PB, Rantakallio P, Hartikainen A-L, Isohanni M, Sipila P: Schizophrenia as a longterm outcome of pregnancy, delivery, and perinatal complications: a 28 -year follow-up of the 1966 north Finland general population birth cohort. Am J Psychiatry 1998;155:355364. 
61 Volpe JJ: Neurobiology of periventricular leukomalacia in the premature infant. Pediatr Res 2001;50:553-562.

- 62 Hack M, Taylor H, Drotar D, Schluchter M, Cartar L, Andreias L, Wilson-Costello D, Klein N: Chronic conditions, functional limitations, and special health care needs of school-aged children born with extremely low birth weight in the 1990s. JAMA 2005;294: 318-325.

63 Litt J, Taylor H, Klein N, Hack M: Learning disabilities in children with very low birthweight: prevalence, neuropsychological correlates and educational interventions. J Learn Disabil 2005;8:130-141.

-64 Tyler WA, Gangoli N, Gokina P, Kim HA, Covey M, Levison SW, Wood TL: Activation of the mammalian target of rapamycin (mTOR) is essential for oligodendrocyte differentiation. J Neurosci 2009;29:6367-6378.

- 65 Sprooten E, Sussmann JE, Moorhead TW, Whalley HC, Ffrench-Constant C, Blumberg HP, Bastin ME, Hall J, Lawrie SM, McIntosh AM: Association of white matter integrity with genetic variation in an exonic DISC1 SNP. Mol Psychiatry 2011;16:688-689.

66 Weinberger RD, Marenco S: Schizophrenia as a neurodevelopmental disorder; in Hirsch SR, Weinberger DR (eds): Schizophrenia, ed 2. London, Blackwell Publishing, 2003, pp 326348.

67 Whitford TJ, Grieve SM, Farrow TF, Gomes L, Brennan J, Harris AW, Gordon E, Williams LM: Progressive grey matter atrophy over the first 2-3 years of illness in first-episode schizophrenia: a tensor-based morphometry study. Neuroimage 2006;32:511-519.

68 Benveniste EN: Cytokine actions in the central nervous system. Cytokine Growth Factor Rev 1998;9:259-275.

-69 Mehler MF, Kessler JA: Hematolymphopoietic and inflammatory cytokines in neural development. Trends Neurosci 1997;20:357365.

70 Mousa A, Seiger A, Kjaeldgaard A, Bakhiet M: Human first trimester forebrain cells express genes for inflammatory and anti-inflammatory cytokines. Cytokine 1999;11:55-60.

-71 Shen Q, Li ZQ, Sun Y, Wang T, Wan CL, Li XW, Zhao XZ, Feng GY, Li S, St Clair D, He $\mathrm{L}, \mathrm{Yu} \mathrm{L}$ : The role of pro-inflammatory factors in mediating the effects on the fetus of prenatal undernutrition: implications for schizophrenia. Schizophr Res 2008;99:48-55.

-72 Chew LJ, King WC, Kennedy A, Gallo V: Interferon-gamma inhibits cell cycle exit in differentiating oligodendrocyte progenitor cells. Glia 2005;52:127-143.

-73 Strle K, Broussard SR, McCusker RH, Shen WH, Johnson RW, Freund GG, Dantzer R, Kelley KW: Proinflammatory cytokine impairment of insulin-like growth factor 1-induced protein synthesis in skeletal muscle myoblasts requires ceramide. Endocrinology 2004; 145:4592-4602.

74 Gavino R, Johnson L, Bhandari V: Release of cytokines and apoptosis in fetal rat type II pneumocytes exposed to hyperoxia and nitric oxide: modulatory effects of dexamethasone and pentoxifylline. Cytokine 2002;20:247-255.

75 Nakazawa T, Nakazawa C, Matsubara A, Noda K, Hisatomi T, She H, Michaud N, Hafezi-Moghadam A, Miller JW, Benowitz LI: Tumor necrosis factor-alpha mediates oligodendrocyte death and delayed retinal ganglion cell loss in a mouse model of glaucoma. J Neurosci 2006;26:12633-12641.

76 Lin W, Harding HP, Ron D, Popko B: Endoplasmic reticulum stress modulates the response of myelinating oligodendrocytes to the immune cytokine interferon-gamma. J Cell Biol 2005;169:603-612.

77 Hanisch U-K, Kettenmann H: Microglia: active sensor and versatile effector cells in the normal and pathologic brain. Nat Neurosci 2007;10:1387-1394.

78 Jonas RA, Yuan T-F, Liang Y-X, Jonas JB, Tay DKC, Ellis-Behnke RG: The spider effect: morphological and orienting classification of microglia in response to stimuli in vivo. PLoS One 2012; 7:e30763.

79 Paolicelli RC, Bolasco G, Pagani F, Maggi L, Scianni M, Panzanelli P, Giustetto M, Ferreira TA, Guiducci E, Dumas L, Ragozzino D, Gross CT: Synaptic pruning by microglia is necessary for normal brain development. Science 2011;333:1456-1458.

80 Vinet J, van Weering HR, Heinrich A, Kalin RE, Wegner A, Brouwer N, Heppner FL, van Rooijen N, Boddeke HW, Biber K: Neuroprotective function for ramified microglia in hippocampal excitotoxicity. J Neuroinflammation 2012;9:27.

-81 Kawanokuchi J, Mizuno T, Takeuchi H, Kato H, Wang J, Mitsuma N, Suzumura A: Production of interferon-gamma by microglia. Mult Scler 2006; 12:558-564.

82 Bessis A, Bechade C, Bernard D, Roumier A: Microglial control of neuronal death and synaptic properties. Glia 2007;55:233-238.

83 Kettenmann H, Hanisch U-K, Noda M, Verkhratsky A: Physiology of microglia. Physiol Rev 2011;91:461-553.

84 Michelucci A, Heurtaux T, Grandbarbe L, Morga E, Heuschling P: Characterization of the microglial phenotype under specific proinflammatory and anti-inflammatory conditions: effects of oligomeric and fibrillar amyloid-beta. J Neuroimmunol 2009;210:3-12.

-85 Pintado C, Revilla E, Vizuete ML, Jimenez S, Garcia-Cuervo L, Vitorica J, Ruano D, Castano A: Regional difference in inflammatory response to LPS-injection in the brain: role of microglia cell density. J Neuroimmunol 2011; 238:44-51.

86 Hart AD, Wyttenbach A, Perry VH, Teeling JL: Age related changes in microglial phenotype vary between CNS regions: grey versus white matter differences. Brain Behav Immun 2012;26:754-765

87 Kaur C, Dheen ST, Ling EA: From blood to brain: amoeboid microglial cell, a nascent macrophage and its functions in developing brain. Acta Pharmacol Sin 2007;28:1087-1096.
88 Wierzba-Bobrowicz T, Schmidt-Sidor B, Gwiazda E, Lechowicz W, Kosno-Kruszewska E: Major histocompatibility complex class II expression in the frontal and temporal lobes in the human fetus during development. Folia Neuropathol 2000;38:73-77.

-89 Verney C, Monier A, Fallet-Bianco C, Gressens P: Early microglial colonization of the human forebrain and possible involvement in periventricular white matter injury of preterm infants. J Anat 2010;217:436-448.

$\checkmark 90$ Billiards SS, Haynes RL, Folkerth RD, Trachtenberg FL, Liu LG, Volpe JJ, Kinney HC: Development of microglia in the cerebral white matter of the human fetus and infant. J Comp Neurol 2006;497:199-208.

91 Lawson LJ, Perry VH, Dri P, Gordon S: Heterogeneity in the distribution and morphology of microglia in the nomal adult mouse brain. Neuroscience 1990;39:151-170.

-92 Monier A, Adle-Biassette H, Delezoide A-L, Evrard P, Gressens P, Verney C: Entry and distribution of microglial cells in human embryonic and fetal cerebral cortex. J Neuropathol Exp Neurol 2007;66:372-382.

93 Bodeutsch N, Thanos S: Migration of phagocytic cells and development of the murine intraretinal microglial network: an in vivo study using fluorescent dyes. Glia 2000;32:91-101.

94 Rezaie P, Male D: Differentiation, ramification and distribution of microglia within the central nervous system examined. Neuroembryology 2002;1:29-43.

95 Hamilton SP, Rome LH: Stimulation of in vitro myelin synthesis by microglia. Glia 1994;11:326-335.

96 Wohl SG, Schmeer CW, Friese T, Witte OW, Isenmann S: In situ dividing and phagocytosing retinal microglia express nestin, vimentin, and NG2 in vivo. PLoS One 2011;6:e22408.

97 Pouly S, Becher B, Blain M, Antel JP: Expression of a homologue of rat NG2 on human microglia. Glia 1999;27:259-268.

-98 Zhu L, Lu J, Tan SS, Jiang H, He BP: Induced NG2 expressing microglia in the facial motor nucleus after facial nerve axotomy. Neuroscience 2010;166:842-851.

\$9 Gao Q, Lu J, Huo Y, Baby N, Ling EA, Dheen ST: NG2, a member of chondroitin sulfate proteoglycans family mediates the inflammatory response of activated microglia. Neuroscience 2010;165:386-394.

100 Kucharova K, Chang Y, Boor A, Yong VW, Stallcup WB: Reduced inflammation accompanies diminished myelin damage and repair in the NG2 null mouse spinal cord. J Neuroinflammation 2011;8:158.

101 Yokoyama A, Yang L, Itoh S, Mori K, Tanaka J: Microglia, a potential source of neurons, astrocytes, and oligodendrocytes. Glia 2004;45:96-104.

102 Butovsky O, Bukshpan S, Kunis G, Jung S, Schwartz M: Microglia can be induced by IFN-gamma or IL-4 to express neural or dendritic-like markers. Mol Cell Neurosci 2007;35:490-500. 
103 Fiedorowicz A, Figiel I, Zaremba M, Dzwonek K, Oderfeld-Nowak B: The ameboid phenotype of NG2(+) cells in the region of apoptotic dentate granule neurons in trimethyltin intoxicated mice shares antigen properties with microglia/macrophages. Glia 2008;56:209-222.

104 Radu A, Hristescu G, Katsel P, Haroutunian V, Davis KL: Microarray database mining and cell differentiation defects in schizophrenia. Adv Exp Med Biol 2011;696:67-74.

105 Back SA, Rivkees SA: Emerging concepts in periventricular white matter injury. Semin Perinatol 2004;28:405-414.

106 Chew LJ, Takanohashi A, Bell MJ: Microglia and inflammation: impact on developmental brain injuries. Ment Retard Dev Disabil Res Rev 2006;12:105-112.

107 Arnett HA, Mason J, Marino M, Suzuki K, Matsushima GK: TNF alpha promotes proliferation of oligodendrocyte progenitors and remyelination. Nat Neurosci 2001;4: $1116-1122$.

108 Miller BA, Crum JM, Tovar CA, Ferguson AR, Bresnahan JC, Beattie MS: Developmental stage of oligodendrocytes determines their response to activated microglia in vitro. J Neuroinflammation 2007;4:28.

-109 van Berckel BN, Bossong MG, Boellaard R, Kloet R, Schuitemaker A, Caspers E, Luurtsema G, Windhorst AD, Cahn W, Lammertsma AA, Kahn RS: Microglial activation in recent-onset schizophrenia: a quantitative (R)-[ $\left.{ }^{11} \mathrm{C}\right] \mathrm{PK} 11195$ positron emission tomography study. Biol Psychiatry 2008;64:820-822.

110 Doorduin J, de Vries EF, Willemsen AT, de Groot JC, Dierckx RA, Klein HC: Neuroinflammation in schizophrenia-related psychosis: a PET study. J Nucl Med 2009;50: 1801-1807.

-111 Muller N, Wagner JK, Krause D, Weidinger E, Wildenauer A, Obermeier M, Dehning S, Gruber R, Schwarz MJ: Impaired monocyte activation in schizophrenia. Psychiatry Res 2012;198:341-346.

112 Dammann O, Kuban KCK, Leviton A: Perinatal infection, fetal inflammatory response, white matter damage, and cognitive limitations in children born preterm. Ment Retard Dev Disabil Res Rev 2002;8:46-50.

113 Volpe JJ: Neurology of the Newborn, ed 5. Philadelphia, Elsevier, 2008.

114 Halsey CL, Collins MF, Anderson CL: Extremely low birth weight children and their peers. A comparison of school-age outcomes. Arch Pediatr Adolesc Med 1996;150: 790-794.

115 Perlman JM: Neurobehavioral deficits in premature graduates of intensive care- potential medical and neonatal environmental risk factors. Pediatrics 2001;108:13391348.

-116 Thompson DK, Inder TE, Faggian N, Warfield SK, Anderson PJ, Doyle LW, Egan GF: Corpus callosum alterations in very preterm infants: perinatal correlates and 2 year neu- rodevelopmental outcomes. Neuroimage 2012;59:3571-3581.

-117 Vangberg TR, Skranes J, Dale AM, Martinussen $M$, Brubakk AM, Haraldseth O: Changes in white matter diffusion anisotropy in adolescents born prematurely. Neuroimage 2006;32:1538-1548.

-118 Evensen KA, Skranes J, Brubakk AM, Vik T: Predictive value of early motor evaluation in preterm very low birth weight and term small for gestational age children. Early Hum Dev 2009;85:511-518.

119 Lund LK, Vik T, Skranes J, Lydersen S, Brubakk AM, Indredavik MS: Low birth weight and psychiatric morbidity; stability and change between adolescence and young adulthood. Early Hum Dev 2012;88:623629.

120 Lohaugen GCC, Gramstad A, Evensen KA, Martinussen M, Lindqvist S, Indredavik MS, Vik T, Brubakk AM, Skranes J: Cognitive profile in young adults born preterm at very low birthweight. Dev Med Child Neurol 2010;52:1133-1138.

121 Eikenes L, Lohaugen GC, Brubakk A-M, Skranes J, Haberg AK: Young adults born preterm with very low birth weight demonstrate widespread white matter alterations on brain DTI. Neuroimage 2011;54:1774-1785.

122 Keelan JA, Blumenstein M, Helliwell RJ, Sato TA, Marvin KW, Mitchell MD: Cytokines, prostaglandins, and parturition - A review. Placenta 2003;24:S33-S46.

123 Luppi P: How immune mechanisms are affected by pregnancy. Vaccine 2003;21:33523357.

124 Yoon BH, Romero R, Moon J, Chaiworapongsa T, Espinoza J, Kim YM, Edwin S, Kim JC, Camacho N, Bujold E, Gomez R: Differences in the fetal interleukin-6 response to microbial invasion of the amniotic cavity between term and preterm gestation. J Matern Fetal Neonatal Med 2003;13:32-38.

125 Indredavik MS, Vik T, Heyerdahl S, Kulseng S, Fayers P, Brubakk AM: Psychiatric symptoms and disorders in adolescents with low birth weight. Arch Dis Child Fetal Neonatal Ed 2004;89:F445-F450.

126 Bohnert KM, Breslau N: Stability of psychiatric outcomes of low birth weight. Arch Gen Psychiatry 2008;65:1080-1086.

127 Freedman D, Bao Y, Kremen WS, Vinogradov S, McKeague IW, Brown AS: Birth weight and neurocognition in schizophrenia spectrum disorders. Schizophr Bull 2012, Epub ahead of print.

128 Folkerth RD: Periventricular leukomalacia: overview and recent findings. Pediatr Dev Pathol 2006;9:3-13.

129 Collins MP, Lorenz JM, Jetton JR, Paneth N: Hypocapnia and other ventilation-related risk factors for cerebral palsy in low birth weight infants. Pediatr Res 2001;50:712-719.

130 Kadhim H, Tabarki B, Verellen G, De Prez C, Rona A-M, Sebire G: Inflammatory cytokines in the pathogenesis of periventricular leukomalacia. Neurology 2001;56:1278-1284.
131 Kadhim H, Tabarki B, De Prez C, Rona AM, Sebire G: Interleukin-2 in the pathogenesis of perinatal white matter damage. Neurology 2002;58:1125-1128.

132 Schmitz T, Felderhoff-Mueser U, Sifringer M, Groenendaal F, Kampmann S, Heep A: Expression of soluble Fas in the cerebrospinal fluid of preterm infants with posthemorrhagic hydrocephalus and cystic white matter damage. J Perinat Med 2010;39:8388.

133 Schmitz T, Heep A, Groenendaal F, Hueseman D, Kie S, Bartmann P, Obladen M, Felderhoff-Mueser U: Interleukin-1beta, interleukin-18, and interferon-gamma expression in the cerebrospinal fluid of premature infants with posthemorrhagic hydrocephalus - Markers of white matter damage? Pediatr Res 2007;6:722-726.

134 Inder TE, Warfield SK, Wang H, Huppi PS, Volpe JJ: Abnormal cerebral structure is present at term in premature infants. Pediatrics 2005;115:286-294.

135 Monier A, Evrard P, Gressens P, Verney C: Distribution and differentiation of microglia in the human encephalon during the first two trimesters of gestation. J Comp Neurol 2006;499:565-582.

136 Verney C, Pogledic I, Biran V, Adle-Biassette $\mathrm{H}$, Fallet-Bianco $\mathrm{C}$, Gressens P: Microglial reaction in axonal crossroads is a hallmark of noncystic periventricular white matter injury in very preterm infants. J Neuropathol Exp Neurol 2012;71:251-264.

137 Matute C, Alberdi E, Domercq M, SanchezGomez M-V, Perez-Samartin A, RodriguezAntiguedad A, Perez-Cerda F: Excitotoxic damage to white matter. J Anat 2007;210: 693-702.

138 Khwaja O, Volpe JJ: Pathogenesis of cerebral white matter injury of prematurity. Arch Dis Child Fetal Neonatal Ed 2008; 93:F153-F161.

139 Billiards SS, Haynes RL, Folkerth RD, Borenstein NS, Trachtenberg FL, Rowitch DH, Ligon KL, Volpe JJ, Kinney HC: Myelin abnormalities without oligodendrocyte loss in periventricular leukomalacia. Brain Pathol 2008;18:153-163.

140 Haynes RL, Folkerth RD, Trachtenberg FL, Volpe JJ, Kinney HC: Nitrosative stress and inducible nitric oxide synthase expression in periventricular leukomalacia. Acta Neuropathol (Berl) 2009;118:391-399.

141 Brown AS, Patterson PH: Maternal infection and schizophrenia: implications for prevention. Schizophr Bull 2011;37:284-290.

142 Goines PE, Croen LA, Braunschweig D, Yoshida CK, Grether J, Hansen R, Kharrazi M, Ashwood P, Van de Walter J: Increased midgestational IFN-gamma, IL-4 and IL-5 in women bearing a child with autism: a case-control study. Mol Autism 2011;2:13.

143 Gilmore JH, Jarskog LF: Exposure to infection and brain development: cytokines in the pathogenesis of schizophrenia. Schizophr Res 1997;24:365-367. 
144 Meyer U, Feldon J, Schedlowski M, Yee BK: Immunological stress at the maternal-foetal interface: a link between neurodevelopment and adult psychopathology. Brain Behav Immun 2006;20:378-388.

145 Boksa P: Animal models of obstetric complications in relation to schizophrenia. Brain Res Brain Res Rev 2004;45:1-17.

146 Boksa P: Effects of prenatal infection on brain development and behavior: a review of findings from animal models. Brain Behav Immun 2010;24:881-897.

147 Meyer U, Feldon J, Yee BK: A review of the fetal brain cytokine imbalance hypothesis of schizophrenia. Schizophr Bull 2009;35:959972.

148 Bell MJ, Hallenbeck JM, Gallo V: Determining the fetal inflammatory response in an experimental model of intrauterine inflammation in rats. Pediatr Res 2004;56:541546.

149 Bell MJ, Hallenbeck JM: Effects of intrauterine inflammation on developing rat brain. J Neurosci Res 2002;70:570-579.

150 Baharnoori M, Bhardwaj SK, Srivastava LK: Neonatal behavioral changes in rats with gestational exposure to lipopolysaccharide: a prenatal infection model for developmental neuropsychiatric disorders. Schizophr Bull 2012;38:444-456.

151 Cai Z, Pan ZL, Pang Y, Evans OB, Rhodes PG: Cytokine induction in fetal rat brains and brain injury in neonatal rats after maternal lipopolysaccharide administration. Pediatr Res 2000;47:64-72.

152 Pang Y, Cai Z, Rhodes PG: Disturbance of oligodendrocyte development, hypomyelination and white matter injury in the neonatal rat brain after intracerebral injection of lipopolysaccharide. Brain Res Dev Brain Res 2003;140:205-214.

153 Burd I, Balakrishnan B, Kannan S: Models of fetal brain injury, intrauterine inflammatiion, and preterm birth. Am J Reprod Immunol 2012;67:287-294.

154 Burd I, Bentz AI, Chai J, Gonzalez J, Monnerie $\mathrm{H}$, Le Roux PD, Cohen AS, Yudkoff M, Elovitz MA: Inflammation-induced preterm birth alters neuronal morphology in the mouse fetal brain. J Neurosci Res 2010;88: 1872-1881.

155 Elovitz MA, Brown AG, Breen K, Anton L, Maubert M, Burd I: Intrauterine inflammation, insufficient to induce parturition, still evokes fetal and neonatal brain injury. Int $J$ Neurosci 2011;29:663-671.

156 Wang X, Hellgren G, Lofqvist C, Li W, Hellstrom A, Hagberg H, Mallard C: White matter damage after chronic subclinical inflammation in newborn mice. J Child Neurol 2009;24:1171-1178.

157 Willette AA, Lubach GR, Knickmeyer RC, Short SJ, Styner M, Gilmore JH, Coe CL: Brain enlargement and increased behavioral and cytokine reactivity in infant monkeys following acute prenatal endotoxemia. Behav Brain Res 2011;219:108-115.
158 Lehnardt S, Lachance C, Patrizi S, Lefebvre S, Follett PL, Jensen FE, Rosenberg PA, Volpe JJ, Vartanian T: The toll-like receptor TLR4 is necessary for lipopolysaccharideinduced oligodendrocyte injury in the CNS. J Neurosci 2002;22:2478-2486.

159 Pang Y, Cai Z, Rhodes PG: Effects of lipopolysaccharide on oligodendrocyte progenitor cells are mediated by astrocytes and microglia. J Neurosci Res 2000;62:510 520.

160 Taylor DL, Pirianov G, Holland S, McGinnity CJ, Norman AL, Reali C, Diemel LT, Gveric D, Yeung D, Mehmet H: Attenuation of proliferation in oligodendrocyte precursor cells by activated microglia. J Neurosci Res 2010;88:1632-1644.

161 Pang Y, Campbell L, Zheng B, Fan L, Cai Z, Rhodes P: Lipopolysaccharide-activated microglia induce death of oligodendrocyte progenitor cells and impede their development. Neuroscience 2010;166:464-475.

162 Marcotte ER, Pearson DM, Srivastava LK: Animal models of schizophrenia: a critical review. J Psychiatry Neurosci 2001;26:395410.

163 Wang T, Town T, Alexopoulou L, Anderson JF, Fikrig E, Flavell RA: Toll-like receptor 3 mediates West Nile virus entry into the brain causing lethal encephalitis. Nat Med 2004; 10:1366-1373.

164 Cunningham C, Campion S, Teeling J, Felton L, Perry VH: The sickness behaviour and CNS inflammatory mediator profile induced by systemic challenge of mice with synthetic double-stranded RNA (poly I:C). Brain Behav Immun 2007;21:490-502.

165 Meyer U, Nyffeler M, Engler A, Urwyler A, Schedlowski M, Knuesel I, Yee BK, Feldon J: The time of prenatal immune challenge determines the specificity of inflammationmediated brain and behavioral pathology. J Neurosci 2006;26:4752-4762.

-166 Fortier ME, Kent S, Ashdown H, Poole S, Boksa P, Luheshi GN: The viral mimic, polyinosinic:polycytidylic acid, induces fever in rats via an interleukin-1-dependent mechanism. Am J Physiol Regul Integr Comp Physiol 2004;287:R759-R766.

167 Shi L, Fatemi SH, Sidwell RW, Patterson PH: Maternal influenza infection causes marked behavioral and pharmacological changes in the offspring. J Neurosci 2003; 23:297-302.

168 Zukerman L, Rehavi M, Nachman R, Weiner I: Immune activation during pregnancy in rats leads to a postpubertal emergence of disrupted latent inhibition, dopaminergic hyperfunction, and altered limbic morphology in the offspring: a novel neurodevelopmental model of schizophrenia. Neuropsychopharmacology 2003;28:1778-1789.

169 Bitanihirwe BKY, Peleg-Raibstein D, Mouttet F, Feldon J, Meyer U: Late prenatal immune activation in mice leads to behavioral and neurochemical abnormalities relevant to the negative symptoms of schizophrenia.
Neuropsychopharmacology 2010;35:24622478.

170 Ibi D, Nagai T, Kitahara Y, Mizoguchi H, Koike H, Shiraki A, Takuma K, Kamai H, Noda Y, Nitta A, Nabeshima T, Yoneda Y, Yamada K: Neonatal polyI:C treatment in mice results in schizophrenia-like behavioral and neurochemical abnormalities in adulthood. Neurosci Res 2009;64:297-305.

171 Pacheco-Lopez G, Giovanoli S, Langhans W, Meyer U: Priming of metabolic dysfunctions by prenatal immune activation in mice: relevance to schizophrenia. Schizophr Bull 2011, E-pub ahead of print.

172 Juckel G, Manitz MP, Brune M, Friebe A, Heneka MT, Wolf RJ: Microglial activation in a neuroinflammational animal model of schizophrenia - A pilot study. Schizophr Res 2011;131:96-100.

173 Deleidi M, Hallet PJ, Koprich JB, Chung CY, Isacson O: The Toll-like receptor-3 agonist polyinosinic:polycyticylic acid triggers nigrostriatal dopaminergic degeneration. J Neurosci 2010;30:16091-160101.

174 Cameron JS, Alexopoulou L, Sloane JA, DiBernardo AB, Ma Y, Kosaras B, Flavell R, Strittmatter SM, Volpe JJ, Sidman R, Vartanian T: Toll-like receptor 3 is a potent negative regulator of axonal growth in mammals. J Neurosci 2007;27:13033-13041.

175 Makinodan M, Tatsumi K, Manabe T, Yamauchi T, Makinodan E, Matsuyoshi H, Shimoda S, Noriyama Y, Kishimoto T, Wanaka A: Maternal immune activation in mice delays myelination and axonal development in the hippocampus of the offspring. J Neurosci Res 2008;86:2190-2200.

-176 Schmitz T, Ritter J, Mueller S, FelderhoffMueser U, Chew LJ, Gallo V: Cellular changes underlying hyperoxia-induced delay of white matter development. J Neurosci 2011; 31:4327-4344.

177 Bsibsi M, Nomden A, van Noort JM, Baron W: Toll-like receptors 2 and 3 agonists differentially affect oligodendrocyte survival, differentiation and myelin membrane formation. J Neurosci Res 2012;90:388-398.

178 Steelman AJ, Li J: Poly(I:C) promotes TNFalpha/TNFR1-dependent oligodendrocyte death in mixed glial cultures. J Neuroinflammation 2011;8:89.

179 Zhang Z, Trautmann K, Schleuesener HJ: Microglia activation in rat spinal cord by systemic injection of TLR3 and TLR7/8 agonists. J Neuroimmunol 2005;164:154160.

180 Lee HJ, Kong PJ, Lee SH, Kwon OY, Chun WJ, Kim SS: Differences between lipopolysaccharide and double-stranded RNA in innate immune responses of BV2 microglial cells. Int J Neurosci 2007;117:885-894.

-181 Baud O, Daire JL, Dalmaz Y, Fontaine RH, Krueger RC, Sebag G, Evrard P, Gressens P, Verney C: Gestational hypoxia induces white matter damage in neonatal rats: a new model of periventricular leukomalacia. Brain Pathol 2004;14:1-10. 
182 Golan H, Kashtuzki I, Hallak M, Sorokin Y, Huleihel M: Maternal hypoxia during pregnancy induces fetal neurodevelopmental brain damage: partial protection by magnesium sulfate. J Neurosci Res 2004;78:430441.

183 Boylan GB, Young K, Panerai RB, Rennie JM, Evans DH: Dynamic cerebral autoregulation in sick newborn infants. Pediatr Res 2000;48:12-17.

184 Sanchez-Solis M, Garcia-Marcos L, BoschGimenez V, Perez-Fernandez V, Pastor-Vivero MD, Mondejar-Lopez P: Lung function among infants born preterm, with or without bronchopulmonary dysplasia. Pediatr Pulmonol 2012;47:674-681.

185 Mazur M, Miller RH, Robinson S: Postnatal erythropoietin treatment mitigates neural cell loss after systemic prenatal hypoxicischemic injury. J Neurosurg Pediatr 2010;6: 206-221.

186 Robinson S, Petelenz K, Li Q, Cohen ML, Dechant A, Tabrizi N, Bucek M, Lust D, Miller RH: Developmental changes induced by graded prenatal systemic hypoxic-ischemic insults in rats. Neurobiol Dis 2005; 18 : 568-581.

187 Robinson S, Li Q, Dechant A, Cohen ML: Neonatal loss of gamma-amino butyric acid pathway expression after human perinatal brain injury. J Neurosurg 2006;104:396-408.

$\checkmark 188$ Vannucci SJ, Hagberg H: Hypoxia-ischemia in the immature brain. J Exp Biol 2004;207: 3149-3154.

189 Sheldon RA, Sedik C, Ferriero DM: Strainrelated brain injury in neonatal mice subjected to hypoxia-ischemia. Brain Res 1998; 810:114-122.

190 Follett PL, Rosenberg PA, Volpe JJ, Jensen FE: NBQX attenuates excitotoxic injury in developing white matter. J Neurosci 2000; 20:9235-9241.

191 Follett PL, Deng W, Dai W, Talos DM, Massillon LJ, Rosenberg PA, Volpe JJ, Jensen FE: Glutamate receptor-mediated oligodendrocyte toxicity in periventricular leukomalacia: a protective role for topiramate. J Neurosci 2004;24:4412-4420.

192 Dwyer BE, Nishimura RN, Fujikawa DG: Cerebral hypoxia-ischemia in immature rats: methodological considerations. Exp Neurol 1988;99:772-777.

193 Mujsce DJ, Christensen MA, Vannucci RC: Cerebral blood flow and edema in perinatal hypoxic-ischemic brain damage. Ped Res 1990;27:450-453.

194 Sheldon RA, Chuai J, Ferriero DM: A rat model for hypoxic-ischemic brain damage in very premature infants. Biol Neonate 1996;69:327-341.

-195 Tejkalova H, Kaiser M, Klaschka J, Stastny F: Does neonatal brain ischemia induce schizophrenia-like behavior in young adult rats? Physiol Res 2007;56:815-823.

\196 Delcour M, Russier M, Amin M, Baud O, Paban V, Barbe MF, Coq J-O: Impact of prenatal ischemia on behavior, cognitive abili- ties and neuroanatomy in adult rats with white matter damage. Behav Brain Res 2012; 232:233-244.

197 Huang BY, Castillo M: Hypoxic-ischemic brain injury: imaging findings from birth to adulthood. Radiographics 2008;28:417-439.

198 Cengiz P, Uluc K, Kendigelen P, Akture E, Hutchinson E, Song C, Zhang L, Lee J, Budoff GE, Meyerand E, Sun D, Ferrazzano P: Chronic neurological deficits in mice after perinatal hypoxia and ischemia correlate with hemispheric tissue loss and white matter injury detected by MRI. Dev Neurosci 2011;33:270-279.

199 Fan LW, Lin S, Pang Y, Lei M, Zhang F, Rhodes PG, Cai Z: Hypoxia-ischemia induced neurological dysfunction and brain injury in the neonatal rat. Behav Brain Res 2005;165:80-90.

200 Skoff RP, Bessert DA, Barks JD, Song D, Cerghet M, Silverstein FS: Hypoxic-ischemic injury results in acute disruption of myelin gene expression and death of oligodendroglial precursors in neonatal mice. Int J Dev Neurosci 2001;19:197-208.

201 Back SA, Han BH, Luo NL, Chricton CA, Xanthoudakis S, Tam J, Arvin KL, Holzman DM: Selective vulnerability of late oligodendrocyte progenitors to hypoxia-ischemia. J Neurosci 2002;22:455-463.

202 Azaidi AU, Bessert DA, Ong JE, Xu H, Barks JD, Silverstein FS, Skoff RP: New oligodendrocytes are generated after neonatal hypoxic-ischemic brain injury in rodents. Glia 2004;46:380-390.

203 Segovia KN, McClure M, Moravec M, Luo NL, Wan Y, Gong X, Riddle A, Craig A, Struve J, Sherman LS, Back SA: Arrested oligodendrocyte lineage maturation in chronic perinatal white matter injury. Ann Neurol 2008;63:520-530.

204 Sizonenko SV, Camm EJ, Dayer A, Kiss JZ: Glial responses to neonatal hypoxic-ischemic injury in the rat cerebral cortex. Int J Neurosci 2008;26:37-45.

205 Fan LW, Lin S, Pang Y, Rhodes PG, Cai Z: Minocycline attenuates hypoxia-ischemiainduced neurological dysfunction and brain injury in the juvenile rat. Eur J Neurosci 2006;24:341-350.

206 Lin S, Fan LW, Rhodes PG, Cai Z: Intranasal administration of IGF-1 attenuates hypoxicischemic brain injury in neonatal rats. Exp Neurol 2009;217:361-370.

207 Schmidt-Kastner R, van Os J, Steinbusch H, Schmitz C: Gene regulation by hypoxia and the neurodevelopmental origin of schizophrenia. Schizophr Res 2006;84:253-271.

208 Fagel DM, Ganat Y, Silbereis JC, Ebbitt T, Stewart WB, Zhang H, Ment LR, Vaccarino FM: Cortical neurogenesis enhanced by chronic perinatal hypoxia. Exp Neurol 2006; 199:77-91.

209 Chahboune H, Ment LR, Stewart WB, Rothman DL, Vaccrino FM, Hyder F, Schwartz ML: Hypoxic injury during neonatal development in murine brain: correlation be- tween in vivo dti findings and behavioral assessment. Cereb Cortex 2009;19:2891-2901.

210 Mayoral SR, Omar G, Penn AA: Sex differences in a hypoxia model of preterm brain damage. Pediatr Res 2009;66:248-253.

211 Kaur C, Sivakumar V, Ang LS, Sundaresan A: Hypoxic damage to the periventricular white matter in neonatal brain: role of vascular endothelial growth factor, nitric oxide and excitotoxicity. J Neurochem 2006;98: 1200-1216.

212 Deng W, Pleasure J, Pleasure D: Progress in periventricular leukomalacia. Arch Neurol 2008;65:1291-1295.

213 Sawada M, Suzumura A, Marunouchi T: Cytokine network in the central nervous system and its roles in growth and differentiation of glial and neuronal cells. Int J Dev Neurosci 1995;13:253-264.

214 Kaur C, Rathnasamy G, Ling EA: Roles of activated microglia in hypoxia induced neuroinflammation in the developing brain and the retina. J Neuroimmune Pharmacol 2012, E-pub ahead of print.

215 Weiss J, Takizawa B, McGee A, Stewart WB, Zhang H, Ment LR, Schwartz MA, Strittmatter S: Neonatal hypoxia suppresses oligodendrocyte Nogo-A and increases axonal sprouting in a rodent model for human prematurity. Exp Neurol 2004;189:141-149.

216 Kendler A, Dawson G: Progressive hypoxia inhibits the de novo synthesis of galactosylceramide in cultured oligodendrocytes. J Biol Chem 1990;265:12259-12266.

217 Akundi RS, Rivkees SA: Hypoxia alters cell cycle regulatory protein expression and induces premature maturation of oligodendrocyte precursor cells. PLos One 2009; 4:e4739.

218 Castillo A, Sola A, Baquero H, Neira F, Alvis R, Deulofeut R, Critz A: Pulse oxygen saturation levels and arterial oxygen tension values in newborns receiving oxygen therapy in the neonatal intensive care unit: is $85 \%$ to $93 \%$ an acceptable range? Pediatrics 2008; 121 : 882-889.

219 Felderhoff-Mueser U, Bittigau P, Sifringer M, Jarosz B, Korobowicz E, Mahler L, Piening T, Moysich A, Grune T, Thor F, Heumann R, Buhrer C, Ikonomidou C: Oxygen causes cell death in the developing brain. Neurobiol Dis 2004;17:273-282.

220 Gerstner B, DeSilva TM, Genz K, Armstrong A, Brehmer F, Neve RL, Felderhoff-Mueser U, Volpe JJ, Rosenberg PA: Hyperoxia causes maturation-dependent cell death in the developing white matter. J Neurosci 2008;28:1236-1245.

221 Schmitz T, Endesfelder S, Reinert MC, Klinker F, Muller S, Buhrer C, Liebetanz D: Adolescent hyperactivity and impaired coordination after neonatal hyperoxia. Exp Neurol 2012;235:374-379.

-222 Liebetanz D, Merkler D: Effects of commissural de- and remyelination on motor skill behavior in the cuprizone mouse model of multiple sclerosis. Exp Neurol 2006;202:217-224. 
223 Rhodes JS, Gammie SC, Garland TJ: Neurobiology of mice selected for high voluntary wheel-running activity. Integr Comp Biol 2005;45:438-455.

-224 de Kieviet JF, Piek JP, Aarnoudse-Moens CS, Oosterlaan J: Motor development in very preterm and very low-birthweight children from birth to adolescence: a meta-analysis. JAMA 2009;302:2235-2242.

-225 Aarnoudse-Moens CS, Weisglas-Kuperus N, van Goudoever JB, Oosterlaan J: Metaanalysis of neurobehavioral outcomes in very preterm and/or very low birth weight children. Pediatrics 2009;124:717-728.

-226 Wocadlo C, Rieger I: Motor impairment and low achievement in very preterm children at eight years of age. Early Hum Dev 2008;84: 769-776.

-227 Halmoy A, Klungsoyr K, Skjærven R, Haavik J: Pre- and perinatal risk factors in adults with attention-deficit/hyperactivity disorder. Biol Psychiatry 2012;71:474-481.

-228 Strang-Karlsson S, Raikkonen K, Pesonen AK, Kajantie E, Paavonen EJ, Lahti J, Hovi P, Heinonen K, Jarvenpaa AL, Eriksson JG, Andersson S: Very low birth weight and behavioral symptoms of attention deficit hyperactivity disorder in young adulthood: the Helsinki study of very-low-birth-weight adults. Am J Psychiatry 2008;165:1345-1353.

229 Linnet KM, Wisborg K, Agerbo NJ, Secher PH, Thomsen TB, Henriksen TB: Gestational age, birth weight, and the risk of hyperkinetic disorder. Arch Dis Child 2006;91:655660.

230 Jeyaseelan D, O’Callaghan M, Neulinger K, Shum D, Burns Y: The association between early minor motor difficulties in extreme low birth weight infants and school age attentional difficulties. Early Hum Dev 2006; 82:249-255.

-231 Diamond A: Close interrelation of motor development and cognitive development and of the cerebellum and prefrontal cortex. Child Dev 2000;71:44-56.

-232 Jandl M, Steyer J, Kaschka WP: Adolescent attention deficit hyperactivity disorder and susceptibility to psychosis in adulthood: a review of the literature and a phenomenological case report. Early Interv Psychiatry 2012;6:11-20.

-233 Shen S, Lang B, Nakamoto C, Zhang F, Pu J, Kuan S-L, Chatzi C, Ho S, Mackie I, Brandon NJ, Marquis KL, Day M, Hurko O, McCaig CD, Riedel G, St Clair D: Schizophrenia-related neural and behavioral phenotypes in transgenic mice expressing truncated DISC1. J Neurosci 2008;28:10893-10904.

234 Gerstner B, Buhrer C, Rheinlander C, Polley O, Schuller A, Berns M, Obladen M, Felderhoff-Mueser U: Maturation-dependent oligodendrocyte apoptosis caused by hyperoxia. J Neurosci Res 2006;84:306-315.

-235 Sribnick EA, Wingrave JM, Matzelle DD, Wilford GG, Ray SK, Banik NL: Estrogen attenuated markers of inflammation and decreased lesion volume in acute spinal cord injury in rats. J Neurosci Res 2005;82:283293.

236 Cantarella G, Risuglia N, Lombardo G, Lempereur L, Nicoletti F, Memo M, Bernardini R: Protective effects of estradiol on TRAILinduced apoptosis in a human oligodendrocyte cell line: evidence for multiple sites of interactions. Cell Death Differ 2004;11:503511.

237 Gerstner B, Sifringer M, Dzietko M, Schuller A, Lee J, Simons S, Obladen M, Volpe JJ, Rosenberg PA, Felderhoff-Mueser U: Estradiol attenuates hyperoxia-induced cell death in the developing white matter. Ann Neurol 2007;61:562-573.

238 Mathiasen R, Hansen BM, Forman JL, Kessing LV, Greisen G: The risk of psychiatric disorders in individuals born prematurely in Denmark from 1974 to 1996. Acta Paediatr 2011;100:691-699.

239 Felderhoff-Mueser U, Sifringer M, Polley O, Dzietko M, Leineweber B, Mahler L, Baier M, Bittigau P, Obladen M, Ikonomidou C, Buhrer C: Caspase-1-processed interleukins in hyperoxia-induced cell death in the developing brain. Ann Neurol 2005;57:50-59.

240 Di Nicola M, Cattaneo A, Hepgul N, Di Forti M, Aitchison KJ, Janiri L, Murray RM, Dazzan P, Pariante CM, Mondelli V: Serum and gene expression profile of cytokines in first-episode psychosis. Brain Behav Immun 2012, E-pub ahead of print.

241 Pedrini M, Massuda R, Fries GR, de Bittencourt Pasquali MA, Schnorr CE, Moreira JC, Teixeira AL, Lobato MI, Walz JC, Belmontede-Abreu PS, Kauer-Sant'Anna M, Kapczinski F, Gama CS: Similarities in serum oxidative stress markers and inflammatory cytokines in patients with overt schizophrenia at early and late stages of chronicity. J Psychiatr Res 2012;46:819-824.

242 Girard S, Sebire G, Kadhim H: Proinflammatory orientation of the interleukin 1 system and downstream induction of matrix metalloproteinase 9 in the pathophysiology of human perinatal white matter damage. J Neuropathol Exp Neurol 2010;69:11161129.

243 Procianoy RS, Silveira RC: Association between high cytokine levels with white matter injury in preterm infants with sepsis. Pediatr Crit Care Med 2012;13:183-187.

244 Bass WT, Buescher ES, Hair PS, White LE, Welch JC, Burke BL: Proinflammatory cytokine-receptor interaction model improves the predictability of cerebral white matter injury in preterm infants. Am J Perinatol 2008;25:211-218.

245 Favrais G, van de Looij Y, Fleiss B, Ramanantsoa N, Bonnin P, Stoltenbrug-Didinger G, Lacaud A, Saliba E, Dammann O, Gallego J, Sizonenko S, Hagberg H, Lelièvre V. Gressens P: Systemic inflammation disrupts the developmental program of white matter. Ann Neurol 2011;70:550-565.

246 Cai Z, Lin S, Pang Y, Rhodes PG: Brain injury induced by intracerebral injection of interleukin-1beta and tumor necrosis facoralpha in the neonatal rat. Pediatr Res 2004; 56:377-384.

247 Takahashi JL, Giuliani F, Power C, Imai Y, Yong VW: Interleukin-1beta promotes oligodendrocyte death through glutamate excitotoxicity Ann Neurol 2003;53:588-595.

248 Barger SW, Goodwin ME, Porter MM, Beggs ML: Glutamate release from activated microglia requires the oxidative burst and lipid peroxidation. J Neurochem 2007;101: 1205-1213.

249 Ye ZC, Sontheimer H: Cytokine modulation of glial glutamate uptake: a possible involvement of nitric oxide. Neuroreport 1996; 7 : 2181-2185.

250 Van Noort JM, van den Elsen PJ, van Horssen J, Geurts JJ, van der Valk P, Amor S: Preactive multiple sclerosis lesions offer novel clues for neuroprotective therapeutic strategies. CNS Neurol Disord Drug Targets 2011;10:68-81.

251 Torkildsen O, Brunborg LA, Myhr M-M, Bo L: The cuprizone model for demyelination. Acta Neurol Scand 2008;117:72-76.

252 Hibbits N, Pannu R, Wu TJ, Armstrong RC: Cuprizone demyelination of the corpus callosum in mice correlates with altered social interaction and impaired bilateral sensorimotor coordination. ASN Neuro 2009; 1:e00013.

253 Makinodan M, Yamauchi T, Tatsumi K, Okuda H, Takeda T, Kiuchi K, Sadamatsu M, Wanaka A, Kishimoto T: Demyelination in the juvenile period, but not in adulthood, leads to long-lasting cognitive impairment and deficient social interaction in mice. Prog Neuropsychopharmacol Biol Psychiatry 2009;33:978-985.

-254 Xu H, Yang HJ, Zhang Y, Clough R, Browning R, Li XM: Behavioral and neurobiological changes in C57BL/6 mice exposed to cuprizone Behav Neurosci 2009;123:418429.

255 Yang HJ, Wang H, Zhang Y, Xiao L, Clough RW, Browning R, Li XM, Xu H: Region-specific susceptibilities to cuprizone-induced lesions in the mouse forebrain: implications for the pathophysiology of schizophrenia. Brain Res 2009;13:121-130.

256 Gudi V, Moharregh-Khiabani D, Skripuletz T, Koutsoudaki PN, Kotsiari A, Skuljec J, Trebst C, Stangel M: Regional differences between grey and white matter in cuprizone induced demyelination. Brain Res 2009; 1283:127-138.

257 Remington LT, Babcock AA, Zehntner SP, Owens T: Microglial recruitment, activation, and proliferation in response to primary demyelination. Am J Pathol 2007;170: 1713-1724.

258 Pasquini LA, Calatayud CA, Bertone Una AL, Millet V, Pasquini JM, Soto EF: The neurotoxic effect of cuprizone on oligodendrocytes depends on the presence of pro-inflammatory cytokines secreted by microglia. Neurochem Res 2007;32:279-292. 
259 Skripuletz T, Miller E, Moharregh-Khiabani 271 Girard S, Tremblay L, Lepage M, Sebire G: D, Blank A, Pul R, Gudi V, Trebst C, Stangel M: Beneficial effects of minocycline on cuprizone induced cortical demyelination. Neurochem Res 2010;35:1422-1433.

-260 Xu H, Yang HJ, McConomy B, Browning R, Li XM: Behavioral and neurobiological changes in C57BL/6 mouse exposed to $\mathrm{cu}-$ prizone: effects of antipsychotics. Front Behav Neurosci 2010;4:8.

261 Zhang $\mathrm{Y}$, Zhang $\mathrm{H}$, Wang L, Jiang W, Xu H, Xiao L, Bi X, Wang J, Zhu S, Zhang R, He J, Tan Q, Zhang D, Kong J, Li XM: Quetiapine enhances oligodendrocyte regeneration and myelin repair after cuprizone-induced demyelination. Schizophr Res 2012;138:817.

-262 Schultz C, Temming P, Bucsky P, W. G, Strunk T, Hartel C: Immature anti-inflammatory response in neonates. Clin Exp Immunol 2004;135:130-136.

263 Dordelmann M, Kerk J, Dressler F, Brinkhaus MJ, Bartels DB, Dammann CE, Dork T, Dammann O: Interleukin-10 high producer allele and ultrasound-defined periventricular white matter abnormalities in preterm infants: a preliminary study. Neuropediatrics 2006;37:130-136.

-264 Li YH, Brauner A, Jonsson B, Van der Ploeg I, Soder O, Holst M, Jensen JS, Lagercrantz $\mathrm{H}$, Tullus K: Inhibition of macrophage proinflammatory cytokine expression by steroids and recombinant IL-10. Biol Neonate 2001;80:124-132.

265 Mesples B, Plaisant F, Gressens P: Effects of interleukin-10 on neonatal excitotoxic brain lesions in mice. Brain Res Dev Brain Res 2003;141:25-32.

-266 Pang Y, Rodts-Palenik S, Cai Z, Bennett WA, Rhodes PG: Suppression of glial activation is involved in the protection of IL-10 on maternal E. coli induced neonatal white matter injury. Brain Res Brain Res Rev 2005; 157: 141-149.

267 Rodts-Palenik S, Wyatt-Ashmead J, Pang Y, Thigpen B, Cai Z, Rhodes P, Martin JN, Granger J, Bennett WA: Maternal infectioninduced white matter injury is reduced by treatment with interleukin-10. Am J Obstet Gynecol 2004;191:1387-1392.

268 Wallace KL, Lopez J, Shaffery JP, Wells A, Paul IA, Bennett WA: Interleukin-10/ceftriaxone prevents E. coli-induced delays in sensorimotor task learning and spatial memory in neonatal and adult sprague dawley rats. Brain Res Bull 2010;81:141-148.

269 Rothstein J, Patel S, Regan M, Haenggeli C, Huang D, Bergles D, Jin L, Hoberg M, Vidensky S, Chung D, Toan S, Bruijn L, Su Z, Gupta P, Fisher P: Beta-lactam antibiotics offer neuroprotection by increasing glutamate transporter expression. Nature 2005; 433:73-77.

270 Rumbaugh J, Li G, Rothstein J, Nath A: Ceftriaxone protects against the toxicity of human immunodeficiency virus proteins. J Neurovirol 2007;13:168-172.
IL-1 receptor antagonist protects against placental and neurodevelopmental defects induced by maternal inflammation. J Immunol 2010;184:3997-4005.

272 Fan LW, Tien LT, Zheng B, Pang Y, Rhodes PG, Cai Z: Interleukin-1beta-induced brain injury and neurobehavioral dysfunction in juvenile rats can be attenuated by alpha-phenyl-n-tert-butyl-nitrone. Neuroscience 2010; 168:240-252.

273 Alnaeeli M, Wang L, Piknova B, Rogers H, Li X, Noguchi CT: Erythropoietin in brain development and beyond. Anat Res Int 2012;2012:953264.

-274 Kumral A, Baskin H, Yesilirmak DC, Ergur BU, Aykan S, Genc S, Genc K, Yilmaz O, Tugyan K, Giray O, Duman N, Ozkan H: Erythropoietin attenuates lipopolysaccharide-induced white matter injury in the neonatal rat brain. Neonatology 2007;92:269-278.

275 Henry CJ, Huang Y, Wynne A, Hanke M, Himler J, Bailey MT, Sheridan JF, Godbout JP: Minocycline attenuates lipopolysaccharide (LPS)-induced neuroinflammation, sickness behavior, and anhedonia. J Neuroinflammation 2008;5:15.

276 Sakata H, Niizuma K, Yoshioka H, Kim GS, Jung JE, Katsu M, Narasimhan P, Maier CM, Nishiyama Y, Chan PH: Minocycline-preconditioned neural stem cells enhance neuroprotection after ischemic stroke in rats. J Neurosci 2012;32:3462-3473.

277 Wixey JA, Reinebrant HE, Spencer SJ, Buller KM: Efficacy of post-insult minocycline administration to alter long-term hypoxiaischemia-induced damage to the serotonergic system in the immature rat brain. Neuroscience 2011;182:184-192.

278 Fan L, Pang Y, Lin S, Tien LT, Ma T, Rhodes PG, Cai Z: Minocycline reduces lipopolysaccharide-induced neurological dysfunction and brain injury in the neonatal rat. J Neurosci Res 2005;82:72-82.

279 Defaux A, Zurich MG, Honegger P, MonnetTschudi F: Minocycline promotes remyelination in aggregating rat brain cell cultures after interferon-gamma plus lipopolysaccharide-induced demyelination. Neuroscience 2011;187:84-92.

280 Schmitz T, Endesfelder S, Chew LJ, Zaak I, Buhrer C: Minocycline protects oligodendroglial precursor cells against injury caused by oxygen-glucose deprivation. J Neurosci Res 2012;90:933-944.

-281 Miyaoka T, Yasukawa R, Yasuda H, Hayashida M, Inagaki T, Horiguchi J: Minocycline as adjunctive therapy for schizophrenia: an open-label study. Clin Neuropharmacol 2008;31:287-292.

282 Chaves C, de Marque CR, Wichert-Ana L, Maia-de-Oliveira JP, Itikawa EN, Crippa JA, Zuardi AW, Todd KG, Baker GB, Dursun SM, Hallak JE: Functional neuroimaging of minocycline's effect in a patient with schizophrenia. Prog Neuropsychopharmacol Biol Psychiatry 2010;34:550-552.
283 Pi R, Li W, Lee NT, Chan HH, Pu Y, Chan LN, Sucher NJ, Chang DC, Li M, Han Y: Minocycline prevents glutamate-induced apoptosis of cerebellar granule neurons by differential regulation of $\mathrm{p} 38$ and Akt pathways. J Neurochem 2004;91:1219-1230.

284 Manev R, Manev H: Minocycline, schizophrenia and GluR1 glutamate receptors. Prog Neuropsychoparmacol Biol Psychiatry 2009;33:166.

285 Drew PD, Chavis JA: Inhibition of microglial cell activation by cortisol. Brain Res Bull 2000;52:391-396.

286 Kaur C, Wu CH, Wen CY, Ling EA: The effects of subcutaneous injections of glucocorticoids on amoeboid microglia in postnatal rats. Arch Histol Cytol 1994;57:449-459.

287 Sierra A, Gottfried-Blackmore A, Milner TA, McEwen BS, Bulloch K: Steroid hormone receptor expression and function in microglia. Glia 2008;56:659-674.

288 Gomez-Gonzalez B, Escobar A: Prenatal stress alters microglial development and distribution in postnatal rat brain. Acta Neuropathol (Berl) 2010;119:303-315.

289 Mann SA, Versmold B, Marx R, Stahlhofen S, Dietzel ID, Heumann R, Berger R: Corticosteroids reverse cytokine-induced block of survival and differentiation of oligodendrocyte progenitor cells from rats. J Neuroinflammation 2008;5:39-55.

290 Pang Y, Fan LW, Zheng B, Campbell LR, Cai Z, Rhodes PG: Dexamethasone and betamethasone protect against lipopolysaccharide-induced brain damage in neonatal rats. Pediatr Res 2012;71:552-558.

291 Yeh TF, Lin YJ, Lin HC, Huang CC, Hsieh WS, Lin $\mathrm{CH}$, Tsai $\mathrm{CH}$ : Outcomes at school age after postnatal dexamethasone therapy for lung disease of prematurity. N Engl Med 2004;350:1304-1313.

292 Baud V, Karin M: Signal transduction by tumor necrosis factor and its relatives. Trends Cell Biol 2001;11:372-377.

293 Doyle LW, Ehrenkranz RA, Halliday HL: Dexamethasone treatment after the first week of life for bronchopulmonary dysplasia in preterm infants: a systematic review. Neonatalogy 2010;98:289-296.

-294 Bartzokis G, Lu PH, Amar CP, Raven EP, Detore NR, Altshuler LL, Mitz J, Ventura J, Casaus LR, Luo JS, Subotnik KL, Nuechterlein KH: Long acting injection versus oral risperidone in first-episode schizophrenia: differential impact on white matter myelination trajectory. Schizophr Res 2011;132:35-41.

295 Kato T, Monji A, Hashioka S, Kanba S: Risperidone significantly inhibits interferongamma-induced microglial activation in vitro. Schizophr Res 2007;92:108-115.

296 Bian Q, Kato T, Monji A, Hashioka S, Mizoguchi Y, Horikawa H, Kanba S: The effect of atypical antipsychotics, perospirone, ziprasidone and quetiapine on microglial activation induced by interferon-gamma. Prog Neuropsychopharmacol Biol Psychiatry 2008;32: $42-48$. 
-297 Fendt M, Lex A, Falkai P, Henn FA, Schmitt A: Behavioral alterations in rats following neonatal hypoxia and effects of clozapine: implications for schizophrenia. Pharmacopsychiatry 2008;41:138-145.

298 Goghari VM, Lang DJ, Khorram B, Gotz J, Vandorpe RA, Smith GN, Kopala LC, Barr AM, Honer WG: Anterior internal capsule volumes increase in patients with schizophrenia switched from typical antipsychotics to olanzapine. J Psychopharmacol 2011;25:621629.

299 Narayan S, Kass KE, Thomas EA: Chronic haloperidol treatment results in a decrease in the expression of myelin/oligodendrocyte-related genes in the mouse brain. J Neurosci Res 2007;85:757-765.

- 300 Konopaske GT, Dorph-Peterson KA, Sweet RA, Pierri JN, Zhang W, Sampson AR, Lewis DA: Effect of chronic antipsychotic exposure on astrocyte and oligodendrocyte numbers in macaque monkeys. Biol Psychiatry 2008;63:759-765.

- 301 Xu H, Yang HJ, Rose GM, Li XM: Recovery of behavioral changes and compromised white matter in C57BL/6 mice exposed to cuprizone: effects of antipsychotic drugs. Front Behav Neurosci 2011;5:31.

302 Cai Z, Fan LW, Lin S, Pang Y, Rhodes PG: Intranasal administration of insulin-like growth factor-1 protects against lipopolysaccharide-induced injury in the developing rat brain. Neuroscience 2011;194:195-207.

303 Pang Y, Zheng B, Campbell LR, Fan LW, Cai Z, Rhodes PG: IGF-1 can either protect against or increase LPS-induced damage in the developing rat brain. Pediatr Res 2010; 67:579-584.
304 Aguirre AA, Dupree JL, Mangin JM, Gallo V: A functional role for EGFR signalling in myelination and remyelination. Nat Neurosci 2007;10:990-1002.

305 Vexler ZS, Yenari MA: Does inflammation after stroke affect the developing brain differently than adult brain? Dev Neurosci 2009;31:378-393.

306 Esterberg M, Compton M: Family history of psychosis negatively impacts age at onset, negative symptoms, and duration of untreated illness and psychosis in first-episode psychosis patients. Psychiatry Res 2012;197:23-28.

307 Kawai M, Minabe Y, Takagai S, Ogai M, Matsumoto H, Mori N, Takei N: Poor maternal care and high maternal body mass index in pregnancy as a risk factor for schizophrenia in offspring. Acta Psychiatr Scand 2004;110:257-263.

308 Matheson SL, Shepherd AM, Laurens KR, Carr VJ: A systematic meta-review grading the evidence for non-genetic risk factors and putative antecedents of schizophrenia. Schizophr Res 2011;133:133-142.

309 Piskulic D, Addington J, Cadenhead KS, Cannon TD, Cornblatt BA, Heinssen R, Perkins DO, Seidman LJ, Tsuang MT, Walker EF, Woods SW, McGlashan TH: Negative symptoms in individuals at clinical high risk of psychosis. Psychiatry Res 2012;196:220224.

310 Becker TM, Cicero DC, Cowan N, Kerns JG: Cognitive control components and speech symptoms in people with schizophrenia. Psychiatry Res 2012;196:20-26.

311 Brebion G, Ohlsen RI, Bressen RA, David AS: Source memory errors in schizophrenia, hallucinations and negative symptoms: a synthesis of research findings. Psychol Med 2012;27:1-12.
312 Walterfang M, McGuire PK, Yung AR, Phillips LJ, Velakoulis D, Wood SJ, Suckling J, Bullmore ET, Brewer W, Soulsby B, Desmond P, McGorry PD, Pantelis C: White matter volume changes in people who develop psychosis. Br J Psychiatry 2008;193: 210-215.

313 Reale M, Patruno A, De Lutils MA, Pesce M, Felaco M, Di Giannantonio M, Di Nicola M, Grilli A: Dysregulation of chemo-cytokine production in schizophrenic patients versus healthy controls. BMC Neurosci 2011;12: 1-9.

314 Maycox PR, Kelly F, Taylor A, Bates S, Reid J, Logendra R, Barnes MR, Larminie C, Jones N, Lennon M, Davies C, Hagan JJ, Scorer CA, Angelinetta C, Akbar MT, Hirsch S, Mortimer AM, Barnes TR, de Belleroche J: Analysis of gene expression in two large schizophrenia cohorts identifies multiple changes associated with nerve terminal function. Mol Psychiatry 2009;14:1083-1094.

315 Mistry M, Gillis J, Pavlidis P: Genome-wide expression profiling of schizophrenia using a large combined cohort. Mol Psychiatry 2012, E-pub ahead of print.

316 Dracheva S, Elhakem SL, McGurk SR, Davis KL, Haroutunian V: GAD67 and GAD65 mRNA and protein expression in cerebrocortical regions of elderly patients with schizophrenia. J Neurosci Res 2004;76:581-592.

317 Moyer CE, Delevich KM, Fish KN, AsafuAdjei JK, Sampson AR, Dorph-Peterson KA, Lewis DA, Sweet RA: Reduced glutamate decarboxylase 65 protein within primary auditory cortex inhibitory boutons in schizophrenia. Biol Psychiatry 2012;72:734-743. 